\title{
Grapevine pruning systems and cultivars influence the diversity of wood-colonizing fungi
}

Renaud TRAVADON ${ }^{\mathrm{a}}$, Pascal LECOMTE ${ }^{\mathrm{b}}$, Barka DIARRA ${ }^{\mathrm{b}}$, Daniel P. LAWRENCE ${ }^{\mathrm{a}}$, David RENAULT $^{\mathrm{b}, \mathrm{c}}$, Hernán OJEDA ${ }^{\mathrm{d}}$, Patrice REY ${ }^{\mathrm{b}, \mathrm{c}}$, Kendra BAUMGARTNER ${ }^{\mathrm{f}, *}$

${ }^{a}$ Department of Plant Pathology, University of California, Davis, CA 95616, USA

${ }^{b}$ INRA, UMR 1065 SAVE, Université de Bordeaux, ISVV, CS 20032, 33882 Villenave d'Ornon cedex, France

${ }^{c}$ Université de Bordeaux, ISVV, UMR 1065 SAVE, Bordeaux Sciences Agro, CS 20032, 33882

Villenave d'Ornon cedex, France

${ }^{d}$ INRA, UE0999, Unité expérimentale de Pech Rouge, 11430 Gruissan, France

${ }^{e}$ United States Department of Agriculture - Agricultural Research Service, Crops Pathology and Genetics Research Unit, Davis, CA 95616, USA

* Corresponding author. United States Department of Agriculture - Agricultural Research

Service, Crops Pathology and Genetics Research Unit, Davis, CA 95616, USA.

Tel.: +1 5307547461 .

E-mail addresses: Kendra.Baumgartner@ars.usda.gov (K. Baumgartner), rtravadon@ucdavis.edu (R. Travadon). 


\begin{abstract}
Grapevine wood hosts diverse fungal species, including pathogens that cause grapevine trunk diseases and wood decomposers, with detrimental effects on yields. This study focuses on the effects of two pruning systems, minimal (min-) or spur-pruning, on the community of trunk pathogens and other wood-colonizing fungi in the trunks of two cultivars, Mourvèdre and Syrah. Culture and DNA-based methods were used to describe the fungal communities. In both cultivars, especially Syrah, spur-pruned vines had more wood necrosis than min-pruned vines, and the community of spur-pruned Syrah was distinguished by its Single-Stranded Conformational Polymorphism (SSCP) profile. Diversity profiles of all 88 cultivated taxa and Canonical Correspondence Analyses of the 15 most frequently isolated taxa revealed differences in community structure due to pruning system, trunk location, and/or wood type. Greater levels of wood necrosis may be due to the composition of the fungal community rather than to a greater diversity of taxa.
\end{abstract}

Index descriptors: Biodiversity, Environmental sampling, Fungi, Wood decay, Hill numbers, Vitis vinifera

\title{
1. Introduction
}

Characterization of fungal communities that colonize woody hosts, and how species of wood-colonizing fungi collectively decompose wood, is a topic of study typically focused on forest ecosystems, e.g., (Lindner et al. 2011; Rajala et al. 2011). Wood decomposition, accomplished primarily by fungi, provides the ecosystem service of nutrient cycling. Forest management practices, such as partial thinning and the presence of canopy gaps, have been 
shown to influence the diversity of wood-colonizing fungi (Junninen et al. 2006; Lindner et al. 2006; Brazee et al. 2014). Because the diversity and composition of such communities impacts the rate of wood decomposition, e.g., (Fukami et al. 2010), it is important to identify management practices that promote forest sustainability.

Wood is usually colonized by communities of wood-decomposing fungi, the diversity of which is thought to influence wood decomposition (van der Wal et al. 2013). White-rot and brown-rot fungi (largely basidiomycete species), and soft-rot fungi (ascomycete species), differ in the types of cell wall-degrading enzymes they secrete, and thus they decompose wood at varying rates and to varying degrees (Worrall et al. 1997). Positive interactions between species can be due to substrate-related niche differentiation (resource partitioning); when fungal species decompose different fractions of substrate, a greater number of species can enhance substrate decomposition (Tiunov and Scheu 2005; LeBauer 2010). More diverse fungal communities are more likely to contain strong decomposers, i.e., sampling effect (Loreau and Hector 2001). Also, synergistic interactions among fungal species (e.g., facilitation of cellulose-degrading species by lignin-degrading species) are more likely in communities harboring more species (LeBauer 2010). However, interactions among fungal species may be negative, in particular when fungal species and/or individuals within a species compete for woody substrates. Such antagonistic interactions may divert their metabolic energy away from decomposition and instead toward defense mechanisms (van der Wal et al. 2013).

In agro-ecosystems, wood-decomposer fungi are present in perennial crops, but wood decomposition is not considered an ecosystem service, as it is in forests. Instead, woodcolonizing fungi can disrupt the vasculature and kill fruiting positions of tree crops, thereby impacting yields and reducing the productive lifespan of the orchard, e.g., Panicle blight of 
pistachio (Michailides and Morgan 2004). In grapevines, some wood-colonizing fungi cause internal infections that appear as necrotic wood cankers or discoloration of the wood, which are thought to be due to a combination of enzymatic decomposition of the wood by the fungi (Rolshausen et al. 2008; Valtaud et al. 2009), secretion of fungal toxins (Abou-Mansour et al. 2015), and/or production of phenolic compounds by the host (Lambert et al. 2012). These fungi are, for the most part, taxonomically unrelated ascomycetes, which cause what are collectively known as 'trunk diseases' (Bertsch et al. 2013), including Botryosphaeria dieback (main causal agents are Diplodia seriata, Neofusicoccum parvum), Eutypa dieback (Eutypa lata), Phomopsis dieback (Diaporthe ampelina), and Petri disease and Esca (Phaeomoniella chlamydospora, Phaeoacremonium minimum).

Grapevine trunk pathogens often cause mixed infections; it is rare to encounter a single grapevine infected with a single species (Péros et al. 1999; Urbez-Torres et al. 2006; Luque et al. 2009; Baumgartner et al. 2013). Virulence varies within and among species of trunk pathogens (Urbez-Torres and Gubler 2009; Travadon and Baumgartner 2015), and a common perspective on such mixed infections is that certain combinations are lethal. Multiple trunk pathogens and other wood-colonizing fungi may interact in the process of wood decomposition (Sparapano et al. 2000). Resource partitioning might be relevant in the process of such wood decomposition because different pathogens may decompose distinct woody substrates, leading to facilitative interactions. A case of facilitative interactions among grapevine trunk pathogens has recently been demonstrated, where co-inoculations of Ilyonectria and Botryosphaeriaceae isolates resulted in more severe grapevine decline than inoculations with Ilyonectria alone (WhitelawWeckert et al. 2013). Nonetheless, very little is known regarding the relationship between fungal 
diversity and wood decomposition in agricultural settings in general and in vineyards in particular.

Just as certain logging practices affect communities of wood-colonizing fungi in forest trees (Lindner et al. 2006), so may vineyard practices that affect fungal colonization of grapevine wood. The influence of vineyard management practices on communities of endophytic fungi in green stems has been illustrated (Pancher et al. 2012), though no such study has examined the effects of vineyard practices on the wood mycobiota. Nonetheless, modifications to the timing of dormant-season pruning, practices known as 'delayed pruning' (Petzoldt et al. 1981; van Niekerk et al. 2011) and 'double pruning' (Weber et al. 2007), have been shown to minimize pruning-wound infections by trunk pathogens. Another approach to minimize infection is to adopt training and pruning systems that require fewer pruning wounds, thereby reducing the number of possible infection courts. Vines trained to a head, rather than to bilateral cordons, for example, have been shown to have a lower incidence of Eutypa dieback (Gu et al. 2005). We tested the hypothesis that a minimal-pruning system, with fewer pruning wounds per vine, is also associated with less wood necrosis and fewer trunk pathogens than a standard, spur-pruning system. Levels of wood necrosis and communities of cultivable fungi were compared in both pruning systems, which were replicated in separate vineyards planted to different wine-grape cultivars, Mourvèdre and Syrah. Understanding how the diversity and composition of fungal communities in the vine wood is affected by pruning, and in turn how the fungal community affects wood decomposition or vascular dysfunction, might help us identify more effective management practices for trunk diseases.

\section{Materials and methods}




\subsection{Study site}

Vines were sampled at Pech Rouge Experimental Station (French National Institute for Agricultural Research (INRA)), Montpellier, located on the Mediterranean Sea in Gruissan, France $\left(43^{\circ} 07^{\prime} 52.94^{\prime \prime} \mathrm{N} ; 3^{\circ} 04^{\prime} 55.31^{\prime} \mathrm{E}\right)$. The study was replicated in two vineyard sites at the station, planted to two different cultivars and separated by $\sim 300 \mathrm{~m}$. Vitis vinifera 'Mourvèdre' was planted in 1999 and 'Syrah' was planted in 1994. Both cultivars were grafted onto rootstock $140 \mathrm{Ru}(V$. berlandieri $\times V$. rupestris $)$ and vines were originally trained to a bilateral-cordon system. Half of the vinerows in each cultivar were either maintained as spur-pruned or converted to minimal pruning, starting in 2003 for the Mourvèdre vineyard and 2002 for the Syrah vineyard. Spur-pruned vines had three to five spurs per cordon, with two to three buds per spur (Fig. 1A). Each dormant season after pruning, a spur-pruned vine thus had at least six to 10 pruning wounds to maintain production of fruitful shoots at the spurs. Minimally pruned (minpruned) vines did not undergo dormant-season pruning. Instead, during the growing season the tips of some of the longest shoots, approximately $1.5 \mathrm{~m}$ distal to the trunk, were trimmed (Fig. 1B).

In September 2012, we surveyed each cultivar for symptoms of trunk diseases. The most apparent trunk disease was Esca, and so we recorded the number of vines out of 74 per cultivar that had shoots with the diagnostic foliar symptoms (Lecomte et al. 2012). Study vines were then selected from sections of the vineyards with no foliar symptoms of Esca. In November 2012, we collected entire vines from adjacent rows: eight min-pruned and eight spur-pruned vines per cultivar (16 vines per cultivar, 32 vines total). Vines were cut off at the base of the trunk, below the graft union, and brought to the laboratory for examination. 


\subsection{Sample collection}

Because of the drastically-different canopy architectures of the two pruning systems (Fig. 1), all of our examinations were carried out on the vine trunks. All trunk pathogens have been associated with discolored wood, either apparent as wood cankers or, in the case of the Esca pathogens, apparent as black spots in cross sections of infected cordons and trunks [e.g., (Kuntzmann et al. 2010a)]. As such, we examined the effects of the pruning system on the proportion of discolored wood (referred to as 'necrosis'). Trunks were cut longitudinally with a band saw. One half of each trunk was then photographed for quantification of necrotic wood, which was, in comparison to apparently healthy wood, darker brown in color and varied in texture from hard to soft and spongy. Necrosis (percentage of trunk area) was quantified from photographs following Liminana et al. (2009). Analysis of Variance (ANOVA) was used to determine the effects of pruning system (minimal pruning, spur pruning), cultivar (Mourvèdre, Syrah), and their interaction on necrosis. Prior to ANOVA, homogeneity of variance across treatments was confirmed using Levene's test. ANOVA was performed using the MIXED procedure in SAS v. 9.4 (SAS Institute Inc., Cary, North Carolina, USA), with all factors treated as fixed effects. For significant effects ( $F$ values with $P \leq 0.05)$, means were compared by Tukey's tests.

To characterize the fungal community from different possible niches for wood-colonizing fungi, we gathered wood samples from four sections of each trunk: trunk top-heartwood, trunk top-sapwood, trunk base-heartwood, and trunk base-sapwood. Each wood sample consisted of approximately $40 \mathrm{~cm}^{3}$ of wood $(10 \times 2 \times 2 \mathrm{~cm})$, excised from the trunk with flame-sterilized pruning shears and stored in $50 \mathrm{~mL}$ Falcon tubes. The trunk top (upper $10 \mathrm{~cm}$; Fig. 2) is closest to the canopy, where pruning wounds are frequently made, and thus may have a greater level of 
colonization/diversity of species (at least in the spur-pruned vines). The trunk base (10 $\mathrm{cm}$ above the graft union; Fig. 2) is closest to the roots, which are potential infection courts for soil-borne spores of the Esca pathogen P. chlamydospora (Ridgway et al. 2005; Retief et al. 2006), for Phaeoacremonium species that have been shown to infect vines through the root system (Adalat et al. 2000), and for the root-infecting fungus Ilyonectria macrodidyma (causal agent of Blackleg or Black-foot disease, previously Cylindrocarpon macrodidymum (Agusti-Brisach et al. 2011)). The trunk base is close to the graft union, which during grafting joins nursery propagation materials (scion and rootstock), contamination of which by trunk-pathogen inoculum has been reported (Gramaje and Armengol 2011).

Within each trunk location (trunk top and trunk base), samples were gathered from two wood types of different ages, the heartwood and the sapwood (Fig. 2). The point of sampling these different wood types was not to demonstrate a relationship between wood necrosis and the presence of trunk pathogens. Indeed, trunk pathogens and other wood-colonizing fungi are reported from both apparently healthy wood, e.g., Maher et al. (2012) and Bruez et al. (2014) and discolored/necrotic wood, e.g., Luque et al. (2009) and Kuntzmann et al. (2010b). Instead, we chose this sampling scheme to focus on xylem of different ages, which might have become infected at different times in the vine's lifespan, and also because other wood-colonizing fungi examined in forest and shade trees (namely basidiomycetes) are often categorized based on their ability to colonize heartwood versus sapwood. The heartwood is the oldest xylem at the central core of the vine trunk (Keller 2015). It is typically discolored (and was uniformly so, in the trunks of the vines we examined), due to high concentrations of phenolic compounds and other plant waste products that build up in the non-functional xylem vessels. The heartwood of grapevines is sometimes decomposing, e.g., by the white-rot fungus $F$. mediterranea (Fischer 
2006), which sometimes colonizes vines also infected by the Esca pathogens (Mugnai et al. 1999). The sapwood represents younger xylem than heartwood. Unlike heartwood, sapwood is rarely uniformly discolored, but can include scattered necrotic sections, as was the case for all vines we examined.

\section{3. Culture-based analysis}

From each wood sample (four samples per vine $\times$ eight vines per pruning system $\times$ two pruning systems per cultivar $\times$ two cultivars $=128$ total samples $), 16$ wood chips (each wood chip was approximately $5 \times 2 \times 2 \mathrm{~mm}$ in size) were surface-sterilized in $5 \%$ calcium hypochlorite for $30 \mathrm{sec}$, rinsed in sterile distilled water, dried on sterile filter paper, and plated (4 wood chips per plate) on two Malt Extract Agar (MEA) and two Potato Dextrose Agar (PDA) plates amended with streptomycin (10\%). Plates were incubated at $25^{\circ} \mathrm{C}$ in darkness for up to 4 weeks, during which fungal colony growth was monitored several times per week. Fungal colonies were subcultured to MEA and were examined after 1 to 2 weeks growth. A total of 193 'morphological taxa' were initially distinguished based on colony and spore morphologies.

Species-level identification was performed on one to two representative isolates per morphological taxon and was based, first, on sequencing of the ribosomal DNA internal transcribed spacer region (ITS), amplified with primers ITS1 and ITS4 (White et al. 1990). We used the methods of Bruez et al. (2014) for mycelium collection, preparation, and DNA extraction. PCR products were purified via Exonuclease I and recombinant Shrimp Alkaline Phosphatase (Affymetrix), and sequenced bidirectionally on an ABI 3730 Capillary Electrophoresis Genetic Analyzer (College of Biological Sciences Sequencing Facility, University of California, Davis). Sequences were proofread and edited using Sequencher v. 5 
(Gene Codes Corporation, Ann Arbor, Michigan, USA). Taxa with ITS sequences of $\geq 98 \%$ similarity were combined into a single operational taxonomic unit (OTU). ITS sequences of the OTUs were then compared to ITS sequences in NCBI using the non-redundant BLASTn database (sequence-identity threshold of $\geq 97 \%$ ). When available in NCBI, ITS sequences from type specimens were used for comparison. For OTUs that could not be assigned at the family or genus levels (i.e., OTUs with $<97 \%$ sequence identity with NCBI sequences), ITS sequences from related taxa, e.g., OTUs within the Diatrypacaeae (Trouillas et al. 2010) or Diaporthaceae (Lawrence et al. 2015), were used for phylogenetic placement (multiple sequence alignments and Neighbor-joining analyses conducted in MEGA v. 6 (Tamura et al. 2013)). For many OTUs belonging to the Dothideomycetes, which did not match ITS sequences in NCBI, we amplified the second largest subunit of RNA polymerase II (RPB2), with primers $\mathrm{f} R P B 2-5 \mathrm{~F}$ and $\mathrm{f} R P B 2$ 7cR (Liu et al. 1999), for taxonomic placement among related members of the Dothideomycetes (Schoch et al. 2009). Using this approach, OTUs, referred to as 'taxa' throughout the manuscript, were categorized to the most refined level of identification (Supplementary material 1). A total of 88 taxa were distinguished from the 193 initial 'morphological taxa', based on either BLASTn searches of homologous sequences in NCBI or phylogenetic analysis of ITS or RPB2. ITS and $R P B 2$ sequences have been deposited in GenBank under the accessions KR909135-KR909222 and $\underline{\text { KT021450-KT021466 }}$, respectively.

\section{4. Diversity and structure of fungal communities}

Separate analyses for pruning system, trunk location and wood type were conducted to evaluate the influence of these three factors on fungal communities, in terms of species richness, diversity, and community composition. For each cultivar, species diversity within a community 
( $\alpha$-diversity) was quantified using Hill numbers (Hill 1973) at four hierarchical levels: first using a dataset that contained all taxa from both pruning systems (min-pruned or spur-pruned), both wood types (heartwood or sapwood), and both trunk locations (top or base); second using a dataset of two assemblages each representing one pruning system; third using a dataset of two assemblages each representing one wood type; and fourth using a dataset of two assemblages each representing one trunk location. In these analyses, experimental units corresponded to wood samples, which represent a combination of wood type and trunk location. Given that the fungi were isolated from 16 tiny wood chips within each sample $\left(\sim 0.25 \mathrm{~cm}^{3}\right.$ from $40 \mathrm{~cm}^{3}$ of wood) and the microscopic nature of filamentous fungi, we assumed that the occurrence of fungal species growing out of one wood chip was little influenced by the occurrence of fungal growth from a distinct wood chip within that same wood sample, thereby ensuring the relative independence of measurements taken within each experimental unit. These considerations also minimized spatial dependency among experimental units. Diversity analyses were based on abundances of cultured taxa, which corresponded to the number of wood samples from which a taxon was isolated, out of 64 total within a cultivar (128 total for the entire study).

The numerous indices that exist in the literature to characterize abundance-based species diversity (e.g., species richness, Shannon entropy, Simpson concentration) can be converted to effective number of species (equivalent to Hill numbers), also called the diversity of order $q$ (Jost 2006, 2007; Ellison 2010; Jost 2010; Dauby and Hardy 2012; Leinster and Cobbold 2012; Chao et al. 2014a), based on the following formula:

${ }^{\mathrm{q}} D \equiv\left(\sum_{\mathrm{i}=1}^{\mathrm{s}} \mathrm{p}_{\mathrm{i}}^{\mathrm{q}}\right)^{1 /(1-\mathrm{q})}, q \geq 0, q \neq 1$.

With $\mathrm{S}$ as the number of species, $p=\left(p_{1}, \ldots, p_{\mathrm{s}}\right)$ the abundance of each species $\left(p_{\mathrm{i}} \geq 0\right)$, and $q$ as the order of the diversity measure (where $0 \leq q \leq \infty$ ), the formula determines the sensitivity of 
the diversity measure to rare species. Rare species contribute less as $q$ increases. When $q=0$, species abundances are not accounted for and ${ }^{0} D$ is equivalent to species richness, the number of effective species in the community. When $q$ approaches 1 , all species are weighted by their frequencies and ${ }^{1} D$ is equivalent to the exponential of Shannon entropy. When $q=2$, abundant species are favored and ${ }^{2} D$ is equivalent to the inverse Simpson concentration. For each order $q$, ${ }^{\mathrm{q}} D$ can be defined as the number of equally abundant species that would give the same ${ }^{\mathrm{q}} D$ value. All Hill numbers are in units of species. They follow the replication principle and can thus be plotted on a graph to express species abundance and diversity. They portray the same information as species accumulation curves (Chao et al. 2014a; Chao et al. 2014b). For $q=0,{ }^{0} D$ and its $95 \%$ confidence limits were estimated using the number of singletons to extrapolate the number of unsampled species (Burnham and Overton 1978). For $q=1,{ }^{1} D$ and $95 \%$ confidence limits were estimated (Chao and Shen 2003). For $q=2,{ }^{2} D$ and $95 \%$ confidence limits were estimated (Chao and Shen 2010). All estimations were conducted in SPADE (Chao and Shen 2003).

The structure of fungal diversity was partitioned into alpha and beta components, and communities were compared between pruning systems, wood types, and trunk locations, separately for each cultivar. Because communities had different weights (i.e., different numbers of wood samples yielding fungal taxa), only ${ }^{1} D$ was decomposed into independent alpha and beta diversity (Jost 2007). The average alpha diversity of order 1 was estimated following equation $11 \mathrm{~b}$ in Jost (2007), where unequal weights are accounted for. Accordingly, the beta diversity of order 1 was given by:

${ }^{1} D \beta={ }^{1} D \gamma /{ }^{1} D \alpha($ eq 9$)$ 
With ${ }^{1} D \gamma$ as the gamma diversity (total diversity across pruning systems, wood types or trunk locations). ${ }^{1} D \beta$ can be interpreted as an effective number of equally likely, completely distinct communities with the same level of diversity. ${ }^{1} D \beta$ can vary from 1 (undifferentiated communities) to 2 (communities share no taxa). Estimations of ${ }^{1} D \beta$ will reveal which factors (pruning system, wood type or trunk location) contribute most to community structure.

\section{5. Relative abundance of the most frequently isolated taxa}

Separate multivariate analyses for each cultivar were conducted to evaluate the influence of pruning system, trunk location and wood type on the 15 most frequently isolated taxa, in terms of relative abundance. Canonical correspondence analysis (CCA) was used to examine the effects of pruning system, trunk location, and wood type on the community structure of the most abundant culturable taxa in each cultivar, using CANOCO (ter Braak and Smilauer 2012). Analyses were based on the frequency of taxa that were present in $\geq 9 \%$ of wood samples in one or both cultivars; species omitted from analyses were present in fewer than 6 of 64 total wood samples per cultivar. To accommodate samples from which no fungi were cultured, 0.000001 was added to all samples for Dip. seriata, the taxon that was present in both cultivars, pruning systems, trunk locations, and wood types. The raw frequency data were first converted into relative abundances, which represent the frequency of a given taxon relative to those of all other taxa present in the sample, and a log transformation was then applied. Interactive forward selection was used to determine the significance of the main effects of cultivar, pruning system, trunk location, and wood type. Factors with significant effects $(P \leq 0.05)$ were retained in the $\mathrm{CCA}$, and factor centroids and taxa vectors (arrows originating from the origin of the axes) were 
displayed in biplots. Proximity of the endpoint of a taxon's vector (arrowhead) to a factor centroid indicates that the taxon played an important role in distinguishing that factor.

\subsection{DNA-based analysis}

In addition to the culture-based analysis, the fungal community was characterized by a DNA-based, culture-independent technique, capillary electrophoresis single-strand conformation polymorphism (CE-SSCP). From each wood sample, approximately $30 \mathrm{~g}$ of wood chips was ground in liquid nitrogen with a one-ball mill of Dangoumau type and kept at $-80^{\circ} \mathrm{C}$ until DNA extraction. DNA was extracted from $60 \mathrm{mg}$ of frozen ground wood, using the Invisorb Spin Plant Mini Kit (Stratec molecular, Germany) following manufacturer's instructions. DNA extracts were quantified with a Nano-drop (ND-1000, Thermoscientific, Labtech) and homogenized at a concentration of $5 \mathrm{ng}^{\mathrm{l}^{-1}}$. Amplification of the fungal mitochondrial large ribosomal subunit DNA was performed using primers $M L 1$ and $M L 2$ (White et al. 1990), according to Bruez et al. (2014). PCR products of $\sim 250 \mathrm{bp}$ were analyzed using CE-SSCP. The CE-SSCP analyses were performed on an ABI PRISM 3130 Genetic Analyzer (Applied Biosystems) equipped with four 36-cm capillaries. One microliter of PCR-product was mixed with $18.8 \mathrm{ml}$ of formamide HiDi (Applied Biosystems) and $0.2 \mathrm{ml}$ of the standard internal DNA size marker Genescan 400HD ROX (Applied Biosystems). The sample mixture was denatured at $95^{\circ} \mathrm{C}$ for $5 \mathrm{~min}$ and immediately cooled on ice prior to CE-SSCP analysis. The nondenaturing polymer consisted of 5.6\% POP conformational analysis polymer (Applied Biosystems), $10 \%$ glycerol, EDTA buffer $(10 \times)$, and water. The migration time was set at 2,000 sec, $32^{\circ} \mathrm{C}$, and $15 \mathrm{kV}$. CE-SSCP is based on the electrophoretic mobility of single-stranded DNA fragments, which reflects their three-dimensional conformation. Larger differences in 
fluorescence scans between migration profiles indicate a greater dissimilarity in composition between samples. Profiles were aligned to the ROX standard internal size marker with the StatFingerprints R-package (Michelland and Cauquil 2010) and adjusted to a common baseline. Numerical values of fluorescence lower than 500 were considered as a background noise and were removed from the database. Principal Component Analysis (PCA) was conducted with the Rcmdr R-package (Fox 2005) to examine similarities of SSCP profiles among the samples.

\section{Results}

\subsection{Internal trunk necrosis}

Pruning had a significant effect on necrosis, based on ANOVA $(P=0.0004)$. As estimated from a view of the wood in a longitudinal section through the vine trunk (Fig. 2), mean necrosis of spur-pruned vines was $35 \%$ ( $n=13$ vines, averaged across cultivars), compared to $21 \%$ for min-pruned vines ( $n=13$ vines, averaged across cultivars). Syrah had twice as much necrosis as Mourvèdre, $37 \%$ versus 19\%, and this difference was significant regardless of pruning system $(P<0.0001$ for main effect of cultivar; no significant Cultivar $\times$ Pruning interaction). Spur-pruned Syrah had the most necrosis (45\%), whereas min-pruned Mourvèdre had the least necrosis (14\%). Although the study vines we examined for wood necrosis did not express Esca symptoms the year of sampling, incidence of such symptoms in the two cultivars showed the same trend as wood necrosis: the percentage of symptomatic vines was higher in Syrah under spur pruning versus minimal pruning ( $46 \%$ versus $16 \%$ ). In Mourvèdre, there were fewer symptomatic vines, but the effect of spur pruning was apparent: $32 \%$ and $12 \%$ for spurpruned and min-pruned vines, respectively. 


\subsection{Diversity profiles and structure of fungal communities}

The diversity profiles allowed comparison of fungal communities of each cultivar between pruning systems, wood types, and trunk locations. The community of cultured fungi consisted of 88 taxa, summed across cultivars, with 37 taxa shared in common between cultivars (Supplementary material 1). At the Mourvèdre vineyard, 63 total taxa were cultured. When considering taxa cultured from fewer than six wood samples as rare, this community included 53 rare taxa. Because this species richness is likely underestimated, we used the number of singletons to estimate the number of unsampled taxa, and this gave a species richness estimate ${ }^{0} D$ of 100.8 [95\% CI of 87.2 to 122$]$ (Fig. 3A). When taxa were weighted in proportion to abundance, diversity ${ }^{1} D$ corresponded to that expected of 44.5 equally abundant taxa [ $95 \% \mathrm{CI}$ of 35.2 to 53.8 . When more weight was placed on the most abundant taxa, diversity ${ }^{2} D$ was equivalent to that expected of 20.6 taxa [ $95 \%$ CI of 16 to 25.3]. In Syrah, the community of cultivable fungi was made up of 62 taxa, including 59 rare taxa. Estimated species richness based on the number of singletons was lower than in Mourvèdre $\left({ }^{0} D=90.9\right.$; Fig. 3B). By comparing the diversity profiles of these two cultivars, the steeper slope between ${ }^{0} D$ and ${ }^{1} D$ revealed a slightly less even distribution of taxa in Mourvèdre, relative to Syrah (Fig. 3A and 3B).

In Mourvèdre, 42 taxa were cultured from minimally pruned vines, compared to 40 taxa from spur-pruned vines, and 19 taxa were shared in common between the two pruning systems. By comparing the diversity profiles of the two pruning systems in Mourvèdre, min-pruned vines had higher diversity values at all orders $q$, indicating a greater fungal diversity than in spurpruned vines (Fig. 3C). In Syrah, 37 taxa were cultured from minimally pruned vines, compared to 43 taxa from spur-pruned vines, and 18 taxa were shared in common between the two pruning 
systems. The comparison of diversity profiles between pruning systems in Syrah (Fig. 3D) revealed a contrasted picture from that of Mourvèdre: spur-pruned Syrah had a greater fungal diversity than min-pruned Syrah, independently of the sensitivity to rare species (for $q=0,1$ and 2).

Comparisons of diversity profiles between wood types (Fig. 3E and 3F) or trunk locations (Fig. 3G and 3H) revealed similar results in both cultivars. First, in each cultivar, species richness was higher in the heartwood than in the sapwood $\left({ }^{0} D=73.8\right.$ vs. 47.8 for Mourvèdre; ${ }^{0} D$ $=74.8$ vs. 61.7 for Syrah), and when more weight was placed on the most abundant species $\left({ }^{2} D\right)$, the sapwood of each cultivar harbored a slightly higher diversity of the most abundant fungal taxa. Second, in each cultivar, species richness was higher at the base than at the top of the trunks ( $\left({ }^{0} D=69.8\right.$ vs. 63.7 for Mourvèdre; ${ }^{0} D=69.8$ vs. 60.8 for Syrah). These differences in diversity between trunk locations tended to disappear for values of ${ }^{1} D$ and ${ }^{2} D$.

In Mourvèdre, the decomposition of the total gamma diversity into its alpha and beta components yielded a beta diversity of order $1{ }^{1} D \beta$ of 1.63 between pruning systems, suggesting there were 1.63 effective distinct communities across the two pruning systems. An even higher beta diversity value for the wood types $\left({ }^{1} D \beta=1.69\right)$, however, suggested this was the most differentiating factor between fungal communities in Mourvèdre ( ${ }^{1} D \beta=1.62$ for trunk locations). In Syrah, beta diversity was highest $\left({ }^{1} D \beta=1.71\right)$ between pruning systems $\left({ }^{1} D \beta=1.59\right.$ for wood types, ${ }^{1} D \beta=1.63$ for trunk locations), suggesting there were greater differences in the structure of fungal communities between pruning systems.

\section{3. CE-SSCP analysis}

SSCP profiles of the samples were separated primarily by two principal components, $\mathrm{PC} 1$ 
and PC2, which explained 52 and $16 \%$ of the variation (68\% total), respectively. There were differences between SSCP profiles of the heartwood and sapwood for both cultivars (Fig. 4A), as we found with diversity ${ }^{0} D$, which takes all cultured taxa into account (Fig. 3E and 3F). However, unlike diversity ${ }^{0} D$, which showed greater differences in species richness between wood types in Mourvèdre, the confidence ellipses representing the SSCP profiles of Syrahheartwood and Syrah-sapwood were farther apart than those of Mourvèdre (Fig. 4A). SSCP profiles of the two pruning systems were differentiated in both cultivars, but were more differentiated in Syrah $(P=0.001$, Fig. 4B). There were no significant main or interactions effects of trunk location (data not shown).

\section{4. Composition of fungal communities}

Ascomycetes dominated the fungal community, making up 85 of 88 taxa (Supplemental material 1). There were only three basidiomycete taxa (white-rot fungi F. mediterranea and Stereum hirsutum, mite-parasitic fungus Acaromyces ingoldii), which were cultured from seven of the 128 total samples. The ascomycete orders with the most taxa were Pleosporales, Hypocreales, and Xylariales. Among the 15 most frequently isolated taxa, six were known grapevine trunk pathogens, one was a dieback pathogen of another host (Euphorbia), and the remaining eight were either wood-colonizing endophytes (i.e., not reported previously as trunk pathogens, wood-decay fungi, or other wood saprobes) or taxa of unknown ecology (Table 1). Other trunk pathogens (seven taxa) were isolated in this study, including E. lata and Neofusicoccum luteum, but they were among the 73 rare taxa (i.e., they were isolated from fewer than six of 64 total wood samples per cultivar; Supplementary material 1). 
Among the 15 most frequently isolated taxa, which were the focus of CCAs, four of the top five were common to both cultivars, thus demonstrating similarity in species composition (Table 1). The top five taxa from Mourvèdre (starting with the most frequently isolated) were Paraconiothyrium variabile, Dip. seriata, $P$. chlamydospora, $P$. minimum, and Paraconiothyrium brasiliense. The Esca pathogens (P. chlamydospora and P. minimum), which we might expect to isolate, given the presence of symptomatic vines in other sections of the vineyard, were both isolated from $19 \%$ of the 64 total samples from Mourvèdre. The top five taxa from Syrah (starting with the most frequently isolated) were Dip. seriata, $P$. chlamydospora, Aureobasidium pullulans, P. variabile, and P. minimum. From Syrah, Esca pathogens $P$. chlamydospora and $P$. minimum were isolated from $34 \%$ and $13 \%$ of the 64 total samples, respectively.

Consistent with differences in diversity profiles between pruning systems in both cultivars (Fig. 4C and 4D), CCAs showed pruning system to have a significant effect on the 15 most frequently isolated taxa of Mourvèdre $(P=0.002)$ and Syrah $(P=0.004)$. The trunk pathogen community of min-pruned Mourvèdre was composed of Botryosphaeria dieback pathogen N. parvum and Phomopsis dieback pathogen Dia. foeniculina, hence their position on the left side of the CCA biplot near the 'Min-pruned' centroid (Fig. 5A) and their higher relative abundances in samples from min-pruned vines (Table 1). Wood-colonizing endophytes $P$. brasiliense and P. microspora were also associated with min-pruning (Fig. 5A). Spur-pruned Mourvèdre was characterized by higher relative abundances of wood-colonizing endophytes $P$. variabile and Phaeosphaeria species 1 and 2 (Fig. 5A). The trunk pathogen community of spurpruned Syrah was composed of Botryosphaeria dieback pathogens N. parvum and Dip. seriata, Esca pathogen P. minimum, and Phomopsis dieback pathogen Dia. ampelina, hence their 
position on the left side of the CCA biplot near the 'Spur-pruned' centroid (Fig. 5B) and their higher relative abundances in spur-pruned vines (Table 1). The Euphorbia dieback pathogen Fusarium brachygibbosum was associated with spur pruning, as were wood-colonizing endophytes Alternaria tenuissima and Bionectria ochroleuca (Fig. 5B). Min-pruned Syrah was characterized by higher relative abundances of Esca pathogen P. chlamydospora and woodcolonizing endophyte $P$. brasiliense (Fig. 5B), the latter of which was completely absent from spur-pruned Syrah (Table 1).

For five of the 15 most frequently isolated taxa, there were consistent observations in their relative abundance across cultivars. Phaeosphaeria species 1 and 2 had higher relative abundances in spur-pruned Mourvèdre and in Syrah these taxa were present only in samples from spur-pruned vines (Table 1). The two Phomopsis dieback pathogens were associated with different pruning systems across cultivars: D. ampelina was in higher abundance in spur-pruned vines, whereas D. foeniculina was in higher abundance in min-pruned vines. Wood-colonizing endophyte $B$. ochroleuca was in higher abundance in spur-pruned vines, whereas $P$. brasiliense was associated with min-pruned vines.

CCA showed a significant effect of trunk location on the relative abundances of the most frequently isolated taxa in Mourvèdre $(P=0.002)$. Esca pathogen $P$. chlamydospora had a higher relative abundance in the trunk top, and this was consistent across wood types and pruning systems (Table 1). Botryosphaeria dieback pathogen $N$. parvum and wood-colonizing endophyte $P$. variabile were both associated with the trunk base (Fig. 5A). Although not significant in the CCAs, there were fewer of the most frequently isolated taxa in the sapwood than the heartwood of both cultivars (Table 1). 


\section{Discussion}

\section{1. Grapevine wood is inhabited by highly diverse fungal assemblages}

By examining the woody trunk of 32 vines at an experimental station in southern France, culture-dependent and independent techniques allowed us to reveal differences between fungal communities colonizing two cultivars grown in separate vineyards, Mourvédre and Syrah, under two pruning systems. Overall, we isolated 88 fungal taxa, which is likely an underestimate of species richness given the methodological bias of culturing; hence, the high proportion of rare taxa. When using the number of singletons for extrapolation, species richness was estimated as 116 fungal species. From other European studies, high species richness was previously reported from non-necrotic wood of grapevine trunks [85 species (Bruez et al. 2014)], from the trunks of vines with or without the foliar symptoms of Esca [158 species (Hofstetter et al. 2012)], from the trunks of five different cultivars [66 species (Casieri et al. 2009)], and from woody stems, leaves and berries [68 species (Gonzalez and Tello 2011)]. These results highlight the high diversity of fungi present within grapevine wood and are in agreement with the high fungal species richness revealed in other woody plants, e.g. (Giordano et al. 2009).

\section{2. Pruning system does not affect fungal diversity similarly between cultivars}

SSCP profiles revealed differences in pruning systems within each cultivar, which were more pronounced in Syrah. Of the 11 most frequently isolated taxa, eight had higher relative abundances in spur-pruned vs. min-pruned Syrah. Spur-pruned Syrah had a greater fungal diversity than min-pruned Syrah, independent of the sensitivity to rare species. Lastly, fungal communities were more differentiated between pruning systems $\left({ }^{1} D \beta=1.71\right)$ than wood types $\left({ }^{1} D \beta=1.59\right)$ or trunk locations $\left({ }^{1} D \beta=1.63\right)$. In Syrah, our findings suggest that with more 
pruning wounds per vine, there are more opportunities for colonization by a more diverse set of trunk pathogens and other wood-colonizing fungi. In contrast, in Mourvédre, wood type was the most differentiating factor $\left({ }^{1} D \beta=1.69\right)$ regarding the diversity of fungal communities, although communities were distinct between pruning systems $\left({ }^{1} D \beta=1.63\right)$, with six of the 11 most frequently isolated taxa having their higher abundances in spur-pruned vines. However, diversity profiles in Mourvédre showed that fungal diversity was higher in min-pruned vines, independent of the sensitivity to rare species.

These contrasting findings between cultivars, which were located in separate vineyard blocks, could have several, not mutually exclusive explanations. First, the two cultivars could differ in their susceptibility to wood-infecting fungi, as revealed with other cultivars (e.g., Sosnowski et al. (2007), Travadon et al. (2013), Billones-Baaijens et al. (2014)). In Mourvédre, infections by fungal pathogens may have been restricted more efficiently to the heartwood by compartmentalization (Shigo 1984), a process which has been characterized in grape in response to P. chlamydospora (Pouzoulet et al. 2013). Higher susceptibility of Syrah is supported by both the relatively high fungal diversity revealed in its sapwood $\left({ }^{1} D=61.7\right)$, relative to the sapwood of Mourvédre $\left({ }^{1} D=47.8\right)$, and a higher level of wood necrosis revealed in longitudinal trunk sections. Second, the timing of adoption of min-pruning in each cultivar was different, with Syrah vines undergoing spur-pruning eight years after planting, at which time minimal pruning was adopted on half the vinerows. In the Mourvédre vineyard, vines were spur-pruned four years after planting, then min-pruning was adopted. Hence, the longer time of spur pruning in young Syrah vines could have allowed more opportunities for pruning-wound infections by fungal spores than in Mourvédre, resulting in a higher level of wood decomposition. Another possible explanation for the differences in fungal diversity between cultivars could be differences 
in the local 'pool' of fungal species in either vineyard block (Hiscox et al. 2016). The cultivars in the two separate blocks, only $300 \mathrm{~m}$ apart and in similar conditions (climate, soil type, and rootstock), shared only 37 out of 88 total fungal taxa.

Lastly, these conclusions regarding treatment effects (e.g., cultivar) on fungal diversity could have been influenced by our experimental design. We intended to minimize underlying factors that could have caused treatment effect: we examined vines with no foliar symptoms of biotic or abiotic origins, planted in adjacent rows in identical soil and grafted on the same rootstocks. Moreover, the experiment was repeated at two vineyard sites at the same elevation. Wood samples from an individual vine were considered independent replicates. It is possible that community diversity was partially due to variation among vines (e.g., hydric status) within a treatment; the effects of individual host plants could have confounded treatment effects. However, our sampling design of wood samples was necessary to assess the effects of wood type (heartwood, sapwood) and trunk locations (base, top) on fungal colonization, and these multiple measurements likely enhanced the precision of diversity assessment within a single vine.

\section{3. Increased fungal diversity is not necessarily associated with more wood necrosis}

It is generally assumed that increased fungal diversity is associated with enhanced wood decomposition because of resource partitioning and synergistic activities among fungal species (van der Wal et al. 2013). In the present study, a link between higher levels of wood necrosis and higher fungal diversity cannot be directly made: there were more fungal taxa in Mourvédre than in Syrah, yet Mourvédre had less wood necrosis than Syrah. Similarly, when comparing the min-pruned with spur-pruned Mourvédre, the former harbored more fungal taxa, but had less wood necrosis. It could be assumed that wood necrosis is not entirely of fungal origin, but is 
influenced by other biotic and abiotic causes. Wood necrosis could be attributed to frost, although frost is rare at this experimental station on the Mediterranean coast. Wood necrosis has been associated with some viruses, but the vine blocks examined did not show any canopy symptoms of viral diseases. While endophytic bacteria were likely present in the trunks, as has been shown in vines with Esca (Bruez et al. 2015), the abilities of bacteria to decompose recalcitrant lignocellulose in environments where fungi are abundant seem relatively minor (Schneider et al. 2012).

Our sampling scheme did not record the necrotic status of each individual wood chip, as wood chips yielding isolates in culture were sampled from either the heartwood or the sapwood, at the base or top of each vine trunk, independently of the necrotic status of the wood. It is thus difficult to attribute a fungal cause to the wood necrosis. However, grapevine trunk pathogens have been isolated from asymptomatic tissues, beyond discolored wood. For example, soft-rot fungi, such as the Diatrypaceous ascomycete Eutypa lata, are frequently isolated several centimeters ahead of the wood lesions that develop in pathogenicity assays (Sosnowski et al. 2007). The numerous fungal taxa known as trunk pathogens, many of which were isolated from our samples from trunks with varying levels of wood necrosis, have been shown in controlled inoculations to initiate wood discoloration [e.g., Cadophora melinii (Travadon et al. 2015), Diaporthe ampelina (Lawrence et al. 2015), Cryptovalsa ampelina (Luque et al. 2006)]. Some of them produce wood-degrading enzymes in vitro (Rolshausen et al. 2008) and they possess a genomic arsenal to break down wood components (Morales-Cruz et al. 2015). Furthermore, the biochemical response of the grapevine to such fungal infections involves production of phenolic and other defence compounds, which can discolor the wood and have fungistatic activity in vitro 
(Lambert et al. 2012). As such, wood necroses were most likely associated with the fungal infections, either directly or indirectly.

\section{4. The specific composition of fungal communities may explain the sanitary status of trunks}

The fungal communities present in spur-pruned Syrah may have contained efficient wood decomposers, such that qualitative differences in the composition of trunk pathogens contributed to differential levels of wood necrosis between cultivars and pruning systems. The peculiarity of the fungal community composition in spur-pruned Syrah is evidenced based on SSCP profiles and could explain the high level of wood degradation in these vines. Assuming that wood necrosis/discoloration reflects wood decomposition by the trunk pathogens, then different wooddegrading abilities between pathogens, as revealed in a recent comparative genomics study (Morales-Cruz et al. 2015), may help explain different levels of wood necrosis. Between the two Esca pathogens, P. minimum (associated with Syrah spur pruning) can decompose celluloses and hemicelluloses in vitro, whereas $P$. chlamydospora (associated with minimal pruning) cannot (Valtaud et al. 2009). Similarly, of the two Phomopsis dieback pathogens, Dia. ampelina, associated with Syrah spur pruning, is a more aggressive colonizer and causes greater levels of wood discoloration in greenhouse assays than Dia. foeniculina, associated with minimal pruning (Lawrence et al. 2015).

Without multi-year samples, it is difficult to know how the assembly history (i.e., the timing and sequence in which species join a community) led to a more diverse fungal community and more wood necrosis in spur-pruned Syrah vines. In the present study, the identity and abundance of fungal species that first colonized spur-pruned Syrah vines probably determined the identity of secondary colonizers. This single year study could not disentangle such 'priority 
effects', but considering that priority effects are major determinants of community structures in habitats with similar environmental conditions (Hiscox et al. 2015), future research on community assembly history in grapevine wood may identify the most detrimental fungal successions causing the severe trunk diseases epidemics in vineyards.

\section{5. Minimal pruning to manage trunk diseases}

Minimal pruning had three main effects on grapevine sanitary status, relative to spurpruning: in both cultivars it was associated with a lower incidence of Esca-symptomatic vines and less necrotic wood in the trunk, and in Syrah fewer symptomatic vines and less necrotic wood were also associated with a less-diverse fungal community (including fewer virulent trunk pathogens). We anticipate the first two effects are beneficial to grape production and that they minimize the economic losses due to trunk diseases (Kaplan et al. In review). Furthermore, minimal pruning eliminates the high annual expense of pruning, which is second to that of harvest. Minimal pruning has been shown to minimize disease incidence and severity of Eutypa dieback, compared to spur-pruning (Gu et al. 2005). Similarly, a study on Esca in France revealed a lower incidence of wood necrosis in the cordons of vines under a 'Guyot' training system with short cordons ( $\sim 20 \mathrm{~cm}$ in length) versus a 'Lyra' training system with longer cordons $(\sim 80 \mathrm{~cm})$, presumably because the latter had more pruning wounds and the resulting greater levels of necrosis had a more damaging effect on the vascular system (Lecomte et al. 2012).

\section{Conclusions}


Similar communities of wood-pathogenic fungi dominated by the same ascomycete families (e.g., Botryosphaeriaceae, Diaporthaceae, Diatrypaceae, Togniniaceae) we found in grape are described from other horticultural crops, including almond (Gramaje et al. 2012), pistachio (Chen et al. 2014b), and walnut (Chen et al. 2014a). Even though the hosts represent different plant families, vineyards and orchards share in common the practice of pruning, and so we might expect to find similar fungi among the different crops. For example, the two Paraconiothyrium species from our study, which were among the top five most frequently isolated taxa, are also reported from stone fruits (Damm et al. 2008). Some of the virulent trunk pathogens that colonize grape wood (e.g., E. lata) are also related to canker pathogens of hardwood trees (Eutypella parasitica on Acer L. and Cryptosphaeria lignyota on Populus), which are members of the Diatrypaceae. In managed forests, canker diseases have been associated with management practices that create more fresh wounds to the wood, for example through unintentional wounding by mechanical operations during thinning (Oliva et al. 2013). A closer look at communities of pathogenic and saprobic ascomycetes in orchards, as has been done in ours and other studies on grape, may help elucidate the identities and roles of these fungi affecting tree crops around the world (Gramaje et al. 2016). Such information may help practitioners understand which management practices discourage colonization by destructive fungi, and thus may improve the productive lifespan of the host.

\section{Acknowledgements}

Funding for this research comes from a travel fellowship from the organization for Economic Cooperation \& Development (OECD), Cooperative Research Program in Biological Resource Management for Sustainable Agricultural Systems, to K. Baumgartner, and a grant 
from the Specialty Crop Research Initiative, National Institute of Food \& Agriculture (NIFA, grant number 2012-01468) to K. Baumgartner and R. Travadon. Funding for this research to P. Lecomte comes from grants from the Account of Specific Affectation for Agricultural \& Rural Development (CasDAR) and the National Committee of Interoccupations of Wines with Label of origin and with Geographical Indication (CNIV). The local assistance of Marc Heywang, Emmanuelle Zumstein and Jean-Louis Escudier (INRA, Domain of Pech Rouge, Gruissan, France) was also greatly appreciated. USDA is an equal opportunity provider and employer. 


\section{References}

Abou-Mansour, E., Debieux, J.-L., Ramirez-Suero, M., Benard-Gellon, M., Magnin-Robert, M., Spagnolo, A., Chong, J., Farine, S., Bertsch, C., L'Haridon, F., Serrano, M., Fontaine, F., Rego, C., Larignon, P., 2015. Phytotoxic metabolites from Neofusicoccum parvum, a pathogen of Botryosphaeria dieback of grapevine. Phytochemistry 115, 207-215.

Adalat, K., Whiting, C., Rooney, S., Gubler, W.D., 2000. Pathogenicity of three species of Phaeoacremonium spp. on grapevine in California. Phytopathol. Medit. 39, 92-99.

Agusti-Brisach, C., Gramaje, D., Leon, M., Garcia-Jimenez, J., Armengol, J., 2011. Evaluation of vineyard weeds as potential hosts of Black-foot and Petri disease pathogens. Plant Dis. $95,803-810$.

Al-Mahmooli, I.H., Al-Bahri, Y.S., Al-Sadi, A.M., Deadman, M.L., 2013. First report of Euphorbia larica dieback caused by Fusarium brachygibbosum in Oman. Plant Dis. 97, 687. Baumgartner, K., Fujiyoshi, P.T., Travadon, R., Castlebury, L.A., Wilcox, W.F., Rolshausen, P.E., 2013. Characterization of species of Diaporthe from wood cankers of grape in eastern North American vineyards. Plant Dis. 97, 912-920.

Bertsch, C., Ramírez- Suero, M., Magnin- Robert, M., Larignon, P., Chong, J., Abou- Mansour, E., Spagnolo, A., Clément, C., Fontaine, F., 2013. Grapevine trunk diseases: complex and still poorly understood. Plant Pathol. 62, 243-265.

Billones-Baaijens, R., Jones, E.E., Ridgway, H.J., Jaspers, M.V., 2014. Susceptiblity of common rootstock and scion varieties of grapevines to Botryosphaeriaceae species. Australas. Plant Pathol. 43, 25-31. 
Brazee, N.J., Lindner, D.L., D’Amato, A.W., Fraver, S., Forrester, J.A., Mladenoff, D.J., 2014. Disturbance and diversity of wood-inhabiting fungi: Effects of canopy gaps and downed woody debris. Biodiversity Cons. 23, 2155-2172.

Bruez, E., Haidar, R., Alou, M.T., Vallance, J., Bertsch, C., Mazet, F., Fermaud, M., Deschamps, A., Guerin-Dubrana, L., Compant, S., 2015. Bacteria in a wood fungal disease: characterization of bacterial communities in wood tissues of esca-foliar symptomatic and asymptomatic grapevines. Frontiers Microbiol. 6, Article 1137.

Bruez, E., Vallance, J., Gerbore, J., Lecomte, P., Da Costa, J.P., Guerin-Dubrana, L., Rey, P., 2014. Analyses of the temporal dynamics of fungal communities colonizing the healthy wood tissues of Esca leaf-symptomatic and asymptomatic vines. Plos ONE 9, e95928.

Burnham, K.P., Overton, W.S., 1978. Estimation of the size of a closed population when capture probabilities vary among animals. Biometrika 65, 625-633.

Casieri, L., Hofstetter, V., Viret, O., Gindro, K., 2009. Fungal communities living in the wood of different cultivars of young Vitis vinifera plants. Phytopathol. Medit. 48, 73-83.

Chao, A., Chiu, C.-H., Jost, L., 2014. Unifying species diversity, phylogenetic diversity, functional diversity and related similarity/differentiation measures through Hill numbers. Ann. Rev. Ecol. Evol. Systematics 45, 297-324.

Chao, A., Gotelli, N.J., Hsieh, T., Sander, E.L., Ma, K., Colwell, R.K., Ellison, A.M., 2014. Rarefaction and extrapolation with Hill numbers: a framework for sampling and estimation in species diversity studies. Ecol. Monographs 84, 45-67.

Chao, A., Shen, T., 2010. Program SPADE (Species Prediction and Diversity Estimation). $\underline{\text { http://chao.stat.nthu.edu.tw }}$ 
Chao, A., Shen, T.-J., 2003. Nonparametric estimation of Shannon's index of diversity when there are unseen species in sample. Environ. Ecol. Stats. 10, 429-443.

Chen, S.F., Morgan, D.P., Hasey, J.K., Anderson, K., Michailides, T.J., 2014. Phylogeny, morphology, distribution, and pathogenicity of Botryosphaeriaceae and Diaporthaceae from English Walnut in California. Plant Dis. 98, 636-652.

Chen, S.F., Morgan, D.P., Michailides, T.J., 2014. Botryosphaeriaceae and Diaporthaceae associated with panicle and shoot blight of pistachio in California, USA. Fung. Diversity $1-23$.

Damm, U., Verkley, G.J.M., Crous, P.W., Fourie, P.H., Haegi, A., Riccioni, L., 2008. Novel Paraconiothyrium species on stone fruit trees and other woody hosts. Persoonia 20, 9-17.

Dauby, G., Hardy, O.J., 2012. Sampled- based estimation of diversity sensu stricto by transforming Hurlbert diversities into effective number of species. Ecography 35, 661672.

Ellison, A.M., 2010. Partitioning diversity. Ecology 91, 1962-1963.

Fischer, M., 2006. Biodiversity and geographic distribution of Basidiomycetes causing escaassociates white rot in grapevine: a worldwide perspective. Phytopathol. Medit. 45, 3042.

Fox, J., 2005. Getting started with the R commander: a basic-statistics graphical user interface to R. J. Stats. Software 14, 1-42.

Fukami, T., Dickie, I.A., Wilkie, J.P., Paulus, B.C., Park, D., Roberts, A., Buchanan, P.K., Allen, R.B., 2010. Assembly history dictates ecosystem funcitoning: Evidence from wood decomposer communities. Ecol Lett. 13, 675-684. 
Giordano, L., Gonthier, P., Varese, G., Miserere, L., Nicolotti, G., 2009. Mycobiota inhabiting sapwood of healthy and declining Scots pine (Pinus sylvestris L.) trees in the Alps. Fung. Diversity 38, 69-83.

Gonzalez, V., Tello, M.L., 2011. The endophytic mycota associated with Vitis vinifera in central Spain. Fung. Diversity 47, 29-42.

Gramaje, D., Agusti-Brisach, C., Perez-Sierra, A., Moralejo, E., Olmo, D., Mostert, L., Damm, U., Armengol, J., 2012. Fungal trunk pathogens associated with wood decay of almond trees on Mallorca (Spain). Persoonia 28, 1-13.

Gramaje, D., Armengol, J., 2011. Fungal trunk pathogens in the grapevine propagation process: Potential inoculum sources, detection, identification, and management strategies. Plant Dis. 95, 1040-1055.

Gramaje, D., Armengol, J., Mohammadi, H., Banihashemi, Z., Mostert, L., 2009. Novel Phaeoacremonium species associated with Petri disease and esca of grapevine in Iran and Spain. Mycologia 101, 920-929.

Gramaje, D., Baumgartner, K., Halleen, F., Mostert, L., Sosnowski, M.R., Urbez-Torres, J.R., Armengol, J., 2016. Fungal trunk diseases: A problem beyond grapevines? Plant Pathol. $65,355-356$.

Gu, S., Cochran, R.C., Du, G., Hakim, A., Fugelsang, K.C., Ledbetter, J., Ingles, C.A., Verdegaal, P.S., 2005. Effect of training-pruning regimes on Eutypa dieback and performance of 'Cabernet Sauvignon' grapevines. J. Hort. Sci. Biotech. 80, 313-318. Hill, M.O., 1973. Diversity and evenness: a unifying notation and its consequences. Ecology 427-432. 
Hiscox, J., Savoury, M., Johnston, S.R., Parfitt, D., Müller, C.T., Rogers, H.J., Boddy, L., In press. Location, location, location: priority effects in wood decay communities may vary between sites. Env. Microbiol.

Hiscox, J., Savoury, M., Müller, C.T., Lindahl, B.D., Rogers, H.J., Boddy, L., 2015. Priority effects during fungal community establishment in beech wood. ISME J. 9, 2246-2260.

Hofstetter, V., Buyck, B., Croll, D., Viret, O., Couloux, A., Gindro, K., 2012. What if esca disease of grapevine were not a fungal disease? Fung. Diversity 54, 1-17.

Jost, L., 2006. Entropy and diversity. Oikos 113, 363-375.

Jost, L., 2007. Partitioning diversity into independent alpha and beta components. Ecology 88, 2427-2439.

Jost, L., 2010. Independence of alpha and beta diversities. Ecology 91, 1969-1974.

Junninen, K., Simila, M., Kouki, J., Kotiranta, H., 2006. Assemblages of wood-inhabiting fungi along the gradients ot succession and naturalness in boreal pine-dominated forests in Fennoscandia. Ecography 29, 75-83.

Kaplan, J., Travadon, R., Cooper, M.L., Hillis, V., Lubell, M., Baumgartner, K., In review. Identifying economic hurdles to early adoption of preventative practices: The case of trunk diseases in California winegrape vineyards. Wine Econ. Policy

Keller, M., 2015. The Science of Grapevines: Anatomy and Physiology, 2nd ed. Academic Press, London, UK.

Kuntzmann, P., Villaume, S., Larignon, P., Bertsch, C., 2010. Esca, BDA and Eutypiosis: foliar symptoms, trunk lesions and fungi observed in diseased vinestocks in two vineyards in Alsace. Vitis 49, 71-76. 
Lambert, C., Bisson, J., Waffo-Teguo, P., Papastamoulis, Y., Richard, T., Corio-Costet, M.F., Merillon, J.M., Cluzet, S., 2012. Phenolics and their antifungal role in grapevine wood decay: Focus on the Botryosphaeriaceae family. J. Agric. Food Chem. 60, 11589-11868.

Larignon, P., Dubos, B., 1997. Fungi associated with esca disease in grapevine. Eur. J. Plant Pathol. 103, 147-157.

Lawrence, D.P., Travadon, R., Baumgartner, K., 2015. Diversity of Diaporthe species associated with wood cankers of fruit and nut crops in northern California. Mycologia 107, 962-940.

LeBauer, D.S., 2010. Litter degradation rate and $\beta$-glucosidase activity increase with fungal diversity. Canadian journal of forest research 40, 1076-1085.

Lecomte, P., Darrieutort, G., Liminana, J.M., Comont, G., Muruamendiaraz, A., Legorburu, F.J., Choueiri, E., Jreijiri, F., El Amil, R., Fermaud, M., 2012. New insights into Esca of grapevine: The development of foliar symptoms and their association with xylem discoloration. Plant Dis. 96, 924-934.

Leinster, T., Cobbold, C.A., 2012. Measuring diversity: the importance of species similarity. Ecology 93, 477-489.

Liminana, J.-M., Pacreau, G., Boureau, F., Menard, E., David, S., Himonnet, C., Fermaud, M., Goutouly, J.-P., Lecomte, P., Dumot, V., 2009. Inner necrosis in grapevine rootstock mother plants in the Cognac area (Charentes, France). Phytopathol. Medit. 48, 92-100.

Lindner, D.L., Burdsall, H.-H., Stanosz, G., 2006. Species diversity of polyporoid and corticioid fungi in northern hardwood forests with differing management histories. Mycologia 98, 195-217. 
Lindner, D.L., Vasaitis, R., Kubartova, A., Allmer, J., Johannesson, H., Banik, M.T., Stenlid, J., 2011. Initial fungal colonizer affects mass loss and fungal community development in Picea abies logs 6 yr after inoculation. Fung. Ecol. 4, 449-460.

Liu, Y.J., Whelen, S., Hall, B.D., 1999. Phylogenetic relationships among ascomycetes: evidence from an RNA polymerse II subunit. Mol. Biol. Evol. 16, 1799-1808.

Loreau, M., Hector, A., 2001. Partitioning selection and complementarity in biodiversity experiments. Nature 412, 72-76.

Luque, J., Martos, S., Aroca, A., Raposo, R., Garcia-Figueres, F., 2009. Symptoms and fungi associated with declining mature grapevine plants in northeast Spain. J. Plant Pathol. 91, 381-390.

Luque, J., Sierra, D., Torres, E., Garcia, F., 2006. Cryptovalsa ampelina on grapevines in NE Spain: identification and pathogenicity. Phytopathol. Medit. 45, S101-109.

Magurran, A.E., 1988. Ecological Diversity and its Measurement. Princeton University Press Princeton, New Jersey, USA.

Maher, N., Piot, J., Bastien, S., Vallance, J., Rey, P., Guerin-Dubrana, L., 2012. Wood necrosis in Esca-affected vines: types, relationship and possible links with foliar symptom expression. J. Int. Sciences des Vigne et Vin 46, 15-27.

Michailides, T.J., Morgan, D.P., 2004. Panicle and shoot blight of pistachio: A major threat to the California pistachio industry. APSnet Features doi: 10.1094/APSnetFeature-20040104 ,

Michelland, R., Cauquil, L., 2010. StatFingerprints. R package, Version 2.0. http://CRAN.Rproject.org $/$ package $=$ StatFingerprints. 
Morales-Cruz, A., Amrine, K.C.H., Blanco-Ulate, B., Lawrence, D.P., Travadon, R., Rolshausen, P.E., Baumgartner, K., Cantu, D., 2015. Distinctive expansion of gene families associated with plant cell wall degradation, secondary metabolism, and nutrient uptake in the genomes of grapevine trunk pathogens. BMC genomics 16, 469.

Mugnai, L., Graniti, A., Surico, G., 1999. Esca (black measles) and brown wood-streaking: two old and elusive diseases of grapevines. Plant Dis. 83, 404-418.

Oliva, J., Boberg, J.B., Hopkins, A.J.M., Stenlid, J., 2013. Concepts of Epidemiology of Forest Diseases. In: Gonthier, P., Nicolotti, G. (Eds.), Infectious Forest Diseases. CABI, Boston, USA.

Pancher, M., Ceol, M., Corneo, P.E., Longa, C.M.O., Yousaf, S., Pertot, I., Campisano, A., 2012. Fungal endophytic communities in grapevines (Vitis vinifera L.) respond to crop management. App. Environ. Microbiol. 78, 4308-4317.

Péros, J.P., Jamaux-Despreaux, I., Berger, G., Gerba, D., 1999. The potential importance of diversity in Eutypa lata and co-colonising fungi in explaining variation in development of grapevine dieback. Mycol. Res. 103, 1385-1390.

Petzoldt, C.H., Moller, W.J., Sall, M.A., 1981. Eutypa dieback of grapevine: Seasonal differences in infection and duration of susceptibility of pruning wounds. Phytopathology $71,540-543$.

Pouzoulet, J., Jacques, A., Besson, X., Dayde, J., Mailhac, N., 2013. Histopathological study of response of Vitis vinifera cv. Cabernet Sauvignon to bark and wood injury with and without inoculation by Phaeomoniella chlamydospora. Phytopathol. Medit. 52, 313-323. 
Rajala, T., Peltoniemi, M., Hantula, J., Makipaa, R., Pennanen, T., 2011. RNA reveals a succession of active fungi during the decay of Norway spruce logs. Fung. Ecol. 4, 437448.

Retief, E., McLeod, A., Fourie, P., 2006. Potential inoculum sources of Phaeomoniella chlamydospora in South African grapevine nurseries. Eur. J. Plant Pathol. 115, 331-339.

Ridgway, H.J., Steyaert, J.M., Pottinger, B.M., Carpenter, M., Nicol, D., Stewart, A., 2005. Development of an isolate-specific marker for tracking Phaeomoniella chlamydospora infection in grapevines. Mycologia 97, 1093-1101.

Rolshausen, P.E., Greve, L.C., Labavitch, J.M., Mahoney, N.E., Molyneux, R.J., Gubler, W.D., 2008. Pathogenesis of Eutypa lata in grapevine: Identification of virulence factors and biochemical characterization of cordon dieback. Phytopathology 98, 222-229.

Schneider, T., Keiblinger, K.M., Schmid, E., Sterflinger-Gleixner, K., Ellersdorfer, G., Roschitzki, B., Richter, A., Eberl, L., Zechmeister-Boltenstern, S., Riedel, K., 2012. Who is who in litter decomposition? Metaproteomics reveals major microbial players and their biogeochemical functions. ISME J. 6, 1749-1762.

Schoch, C., Crous, P.W., Groenewald, J.Z., Boehm, E., Burgess, T.I., De Gruyter, J., De Hoog, G., Dixon, L., Grube, M., Gueidan, C., 2009. A class-wide phylogenetic assessment of Dothideomycetes. Studies Mycol. 64, 1-15.

Shigo, A.L., 1984. Compartmentalization: a conceptual framework for understanding how trees grow and defend themselves. Ann. Rev. Phytopathol. 22, 189-214.

Sosnowski, M.R., Lardner, R., Wicks, T.J., Scott, E.S., 2007. The influence of grapevine cultivar and isolate of Eutypa lata on wood and foliar symptoms. Plant Dis. 91, 924-931. 
Sparapano, L., Bruno, G., Ciccarone, C., Graniti, A., 2000. Infection of grapevines by some fungi associated with esca. II. Interaction among Phaeoacremonium chlamydosporum, $P$. aleophilum and Fomitiporia punctata. Phytopathol. Medit. 39, 53-58.

Tamura, K., Stecher, G., Peterson, D., Filipski, A., Kumar, S., 2013. MEGA6: Molecular Evolutionary Genetics Analysis, Version 6.0. Mol. Biol. Evol. 30, 2725-2729.

ter Braak, C.J.F., Smilauer, P., 2012. CANOCO Reference Manual and User's Guide: Software for Ordination, Version 5.0. Microcomputer Power, Ithaca, NY, USA.

Tiunov, A.V., Scheu, S., 2005. Facilitative interactions rather than resource partitioning drive diversity- functioning relationships in laboratory fungal communities. Ecology Letters 8, 618-625.

Travadon, R., Baumgartner, K., 2015. Molecular polymorphism and phenotypic diversity in the Eutypa Dieback pathogen Eutypa lata. Phytopathology 105, 255-264.

Travadon, R., Lawrence, D.P., Rooney-Latham, S., Gubler, W.D., Wilcox, W.W., Rolshausen, P.E., Baumgartner, K., 2015. Cadophora species associated with wood decay of grapevine in North America. Fung. Biol 119, 53-66.

Travadon, R., Rolshausen, P.E., Gubler, W.D., Cadle-Davidson, L., Baumgartner, K., 2013. Susceptibility of cultivated and wild Vitis spp. to wood infection by fungal trunk pathogens. Plant Dis. 97, 1529-1536.

Trouillas, F.P., Urbez-Torres, J.R., Gubler, W.D., 2010. Diversity of Diatrypaceous fungi associated with grapevine canker diseases in California. Mycologia 102, 319-336.

Urbez-Torres, J.R., 2011. The status of Botryosphaeriaceae species infecting grapevines. Phytopathol. Medit. 50, S5-S45. 
Urbez-Torres, J.R., Gubler, W.D., 2009. Pathogenicity of Botryosphaeriaceae species isolated from grapevine cankers in California. Plant Dis. 93, 584-592.

Urbez-Torres, J.R., Leavitt, G.M., Voegel, T.M., Gubler, W.D., 2006. Identification and distribution of Botryosphaeria spp. associated with grapevine cankers in California. Plant Dis. $90,1490-1503$.

Valtaud, C., Larignon, P., Roblin, G., Fleurat-Lessard, P., 2009. Developmental and ultrastructural features of Phaeomoniella chlamydospora and Phaeoacremonium aleophilum in relation to xylem degradation in Esca disease of the grapevine. J. Plant Pathol. 91, 37-51.

van der Wal, A., Geydan, T.D., Kuyper, T.W., Boer, W., 2013. A thready affair: linking fungal diversity and community dynamics to terrestrial decomposition processes. FEMS Microbiol. Rev. 37, 477-494.

van Niekerk, J.M., Halleen, F., Fourie, P.H., 2011. Temporal susceptibility of grapevine pruning wounds to trunk pathogen infection in South African grapevines. Phytopathol. Medit. 50, Weber, E.A., Trouillas, F.P., Gubler, W.D., 2007. Double pruning of grapevines: a cultural practice to reduce infections by Eutypa lata. Amer. J. Enol. Vitic. 58, 61-66.

White, T.J., Bruns, T., Lee, S., Taylor, J., 1990. Amplification and direct sequencing of fungal ribosomal RNA genes for phylogenetics. In: Innis, M.A., Gelfand, D. H., Sninsky, J. J., White, T. J. (Eds.), PCR protocols: A Guide to Methods and Applications. Academic Press Inc., New York, pp. 315-322.

Whitelaw-Weckert, M.A., Rahman, L., Appleby, L.M., Hall, A., Clark, A.C., Waite, H., Hardie, W.J., 2013. Co-infection by Botryosphaeriaceae and Ilyonectria spp. fungi during propagation causes decline of young grafted grapevines. Plant Pathol. 62, 1226-1237. 
Worrall, J.J., Anagnost, S.E., Zabel, R.A., 1997. Comparison of wood decay among diverse lignicolous fungi. Mycologia 89, 199-219.

Wunderlich, N., Ash, G.J., Steel, C.C., Raman, H., Savocchia, S., 2011. Association of Botryosphaeriaceae grapevine trunk disease fungi with the reproductive structures of Vitis vinifera. Vitis 50, 89-96. 


\section{Figure Captions.}

Fig. 1. Grapevines were either spur pruned (A) or min-pruned (B). Shown here is Mourvèdre, photographed when vines were sampled in November 2012. Vines were selected for sampling the preceding September, when the foliar symptoms of Esca were apparent. We selected vines from sections of the Mourvèdre and Syrah vineyards with no foliar symptoms of Esca and no foliar or canopy symptoms (dead spurs, stunted shoots, shoot dieback) of other trunk diseases (Botryosphaeria dieback, Eutypa dieback, Phomopsis dieback). Spur-pruned vines had two cordons with a trunk height of approximately $50 \mathrm{~cm}$, whereas min-pruned vines had no cordons and a trunk height of approximately $100 \mathrm{~cm}$.

Fig. 2. Longitudinal section of a vine trunk (A) from spur-pruned Mourvèdre. Wood was sampled from the top $(\mathbf{B})$ and base $(\mathbf{C})$ of each trunk. Within each trunk location, wood was sampled from the heartwood (dashed rectangle) and the sapwood (plain rectangle). Dashed and plain rectangles in panels $\mathrm{B}$ and $\mathrm{C}$ measure approximately $10 \times 2 \mathrm{~cm}$.

Fig. 3. Diversity profiles based on Hill numbers for fungal communities of (A) Mourvèdre and (B) Syrah, of (C, D) min-pruned and spur-pruned vines in either cultivar, of the (E, F) heartwood and sapwood in either cultivar, and of the $(\mathbf{G}, \mathbf{H})$ trunk top and trunk base of either cultivar. The $x$ axis is the order $q$ and the $y$ axis is the diversity of order $q$ (Hill number or the effective number of equally-abundant taxa). For $q=0,{ }^{0} D$ is species richness, which was estimated using the number of singletons to extrapolate the number of missing species (Burnham and Overton 1978). For $q=1,{ }^{1} D$ is the exponential of Shannon diversity, which was estimated following Chao and 
Shen (2003). For $q=2,{ }^{2} D$ is the inverse of Simpson diversity, which was estimated following Magurran (1988) (eq. 2.26). The diversity profile is a non-increasing function of $q$. The slope reflects the unevenness of species' relative abundances. The more uneven the distribution of relative abundances, the steeper the slope. For completely even relative abundances, the curve would be constant at the level of species richness.

Fig. 4. Principal component analysis (PCA) of SSCP profiles for the mitochondrial large ribosomal subunit DNA. Each point represents a sample based on a pairwise, sample-by-sample, distance matrix of the profiles (245 SSCP peaks). Boxes indicate average positions, surrounded by confidence ellipses $(P=0.05)$, for samples grouped by cultivar and wood type $(\mathbf{A})$, cultivar and pruning system (B). Principal component 1 (PC1, $x$ axis) accounts for $52 \%$ of total variation, PC2 ( $y$ axis) accounts for $16 \%$.

Fig. 5. Biplots of canonical correspondence analyses (CCA) of the 15 most frequently cultured taxa in (A) Mourvèdre and (B) Syrah. Centroids for the pruning systems (Min-pruning, Spur pruning) and trunk locations (Trunk top, Trunk base) are shown in relation to vectors (arrows) for each taxon. Proximity of a vector to a centroid indicates a higher relative abundance of a taxon in such samples. Both axes of $\mathbf{A}$ are significant $(P=0.002)$, with Axis $1(x$ axis $)$ accounting for $20 \%$ of total variation, axis $2(y$ axis) for $19 \%$. Both axes of $\mathbf{B}$ are significant $(P=$ 0.002 ), with Axis 1 ( $x$ axis) accounting for $22 \%$ of total variation, axis $2(y$ axis) for $10 \%$. 
A

tis

2.

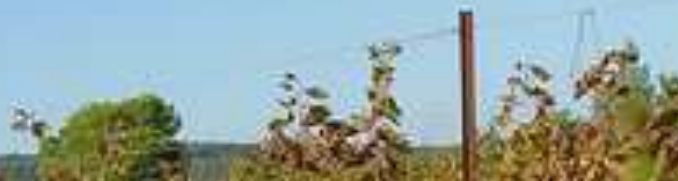

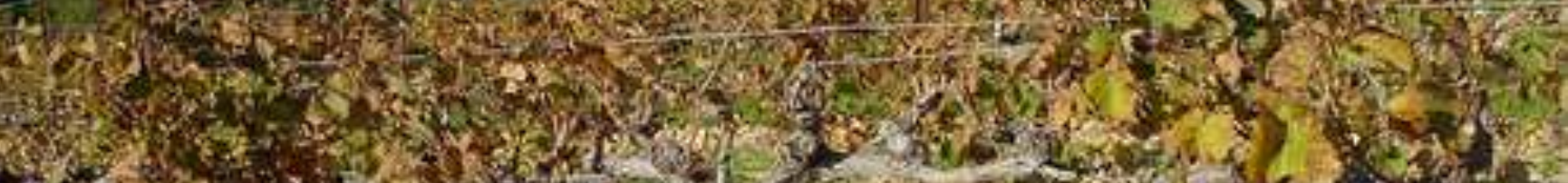

|l $x_{3}=x^{2}$

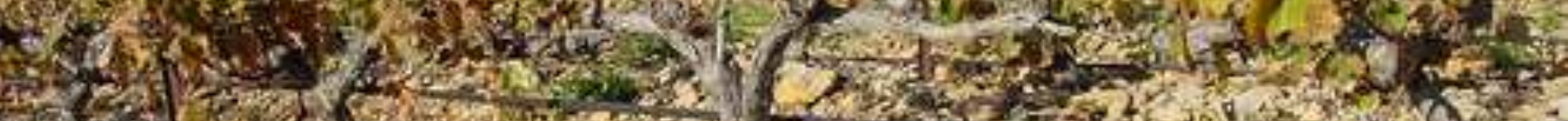

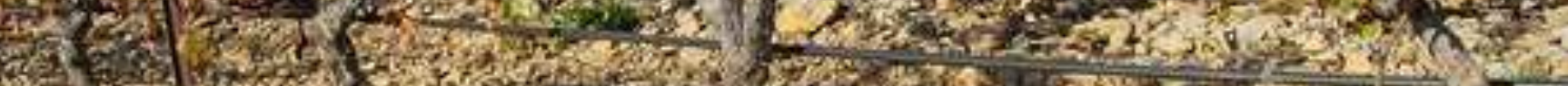
201 (3)

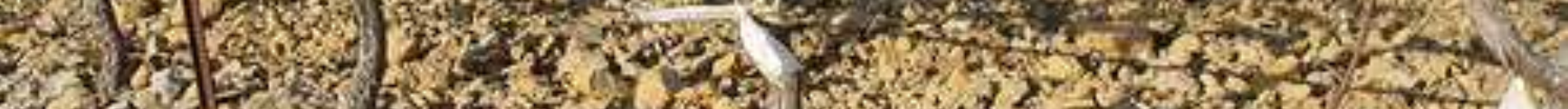

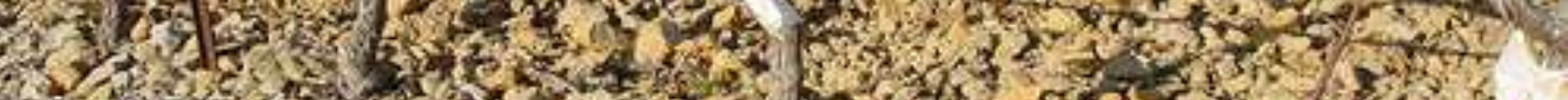

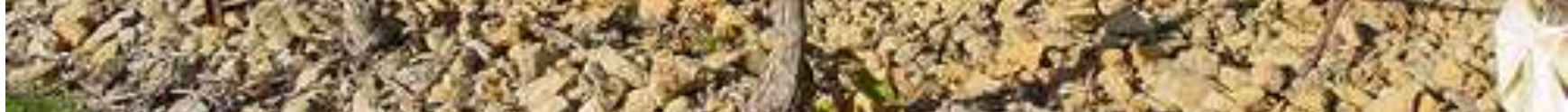

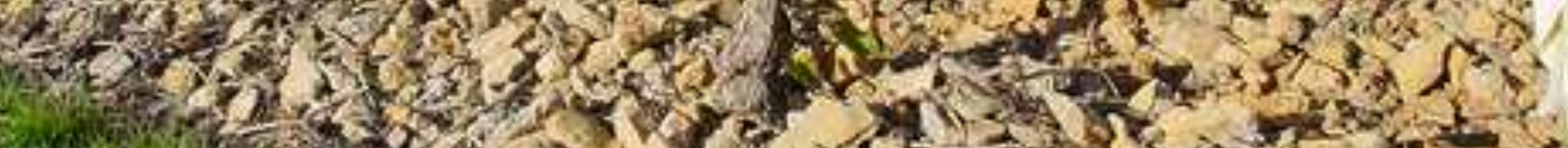

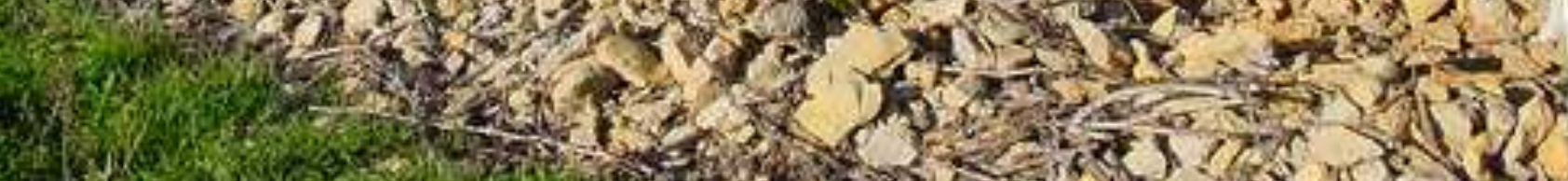

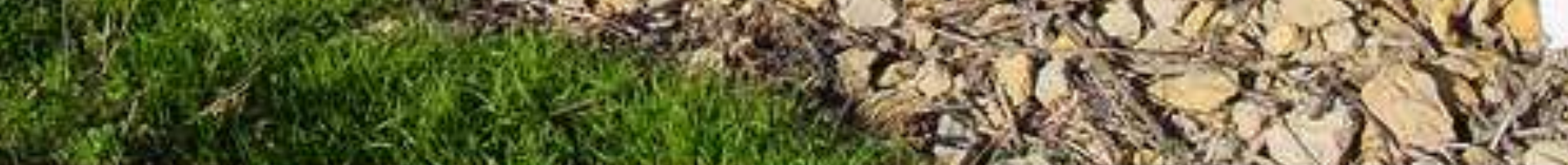

B

$\%$

$+\infty$

$\operatorname{los}^{2}+x^{2+2}$

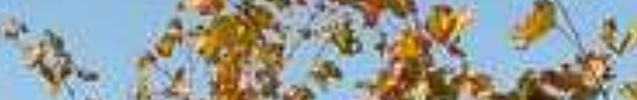

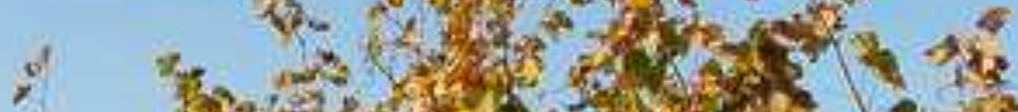

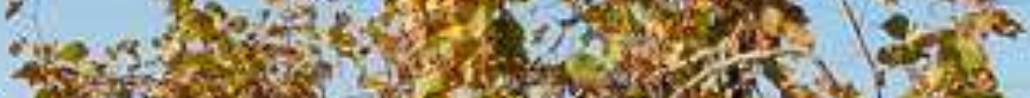

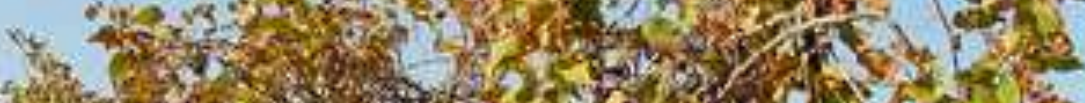

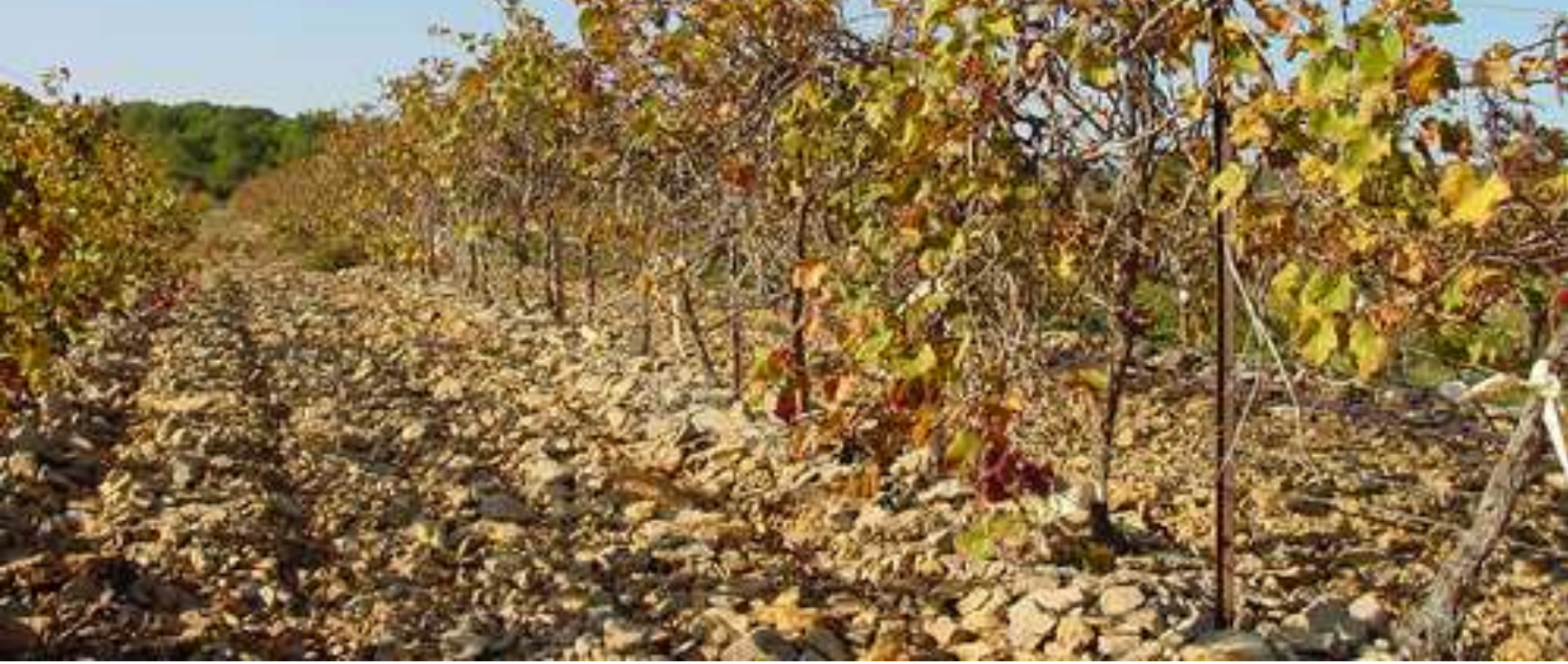



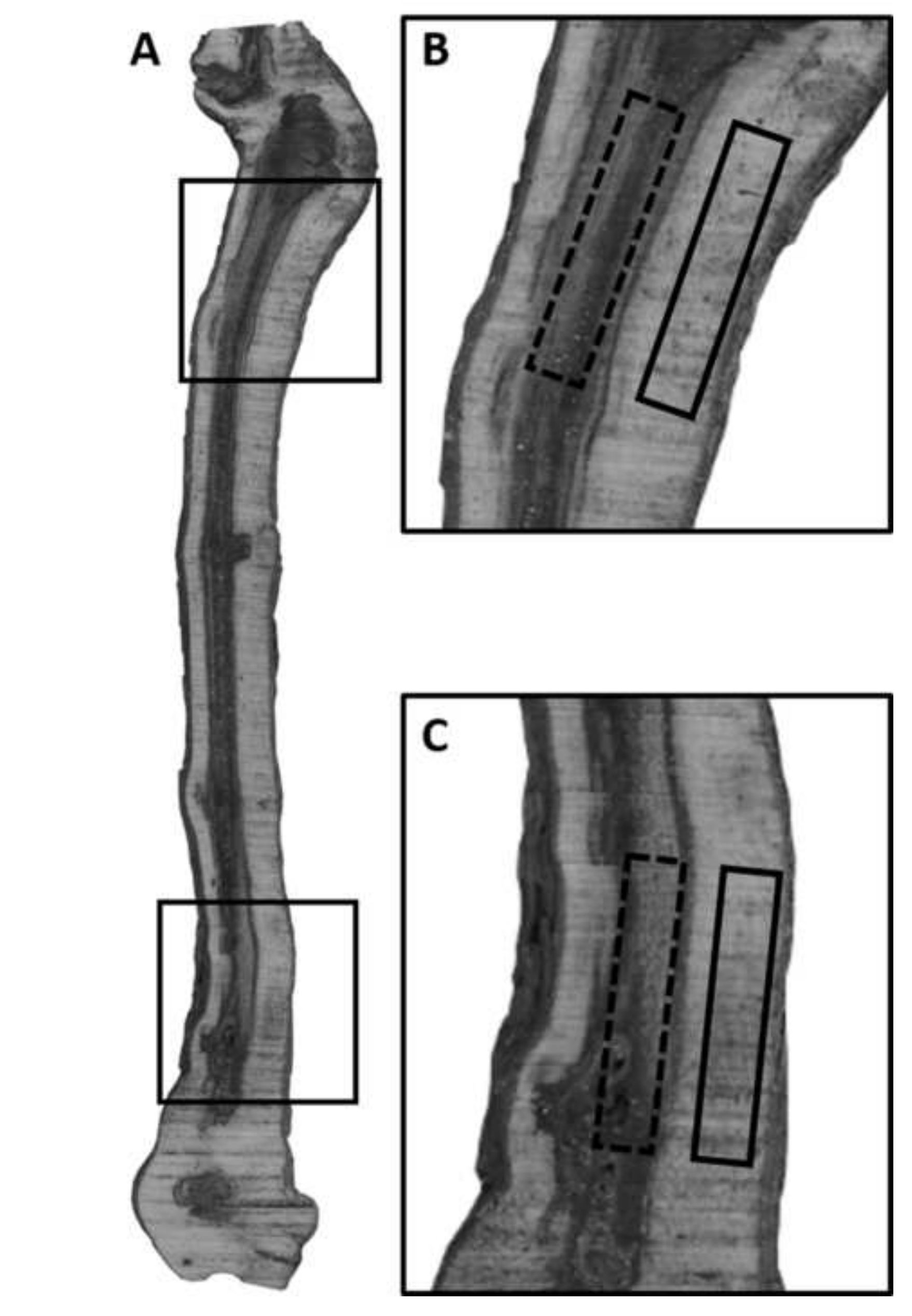

Figure 2

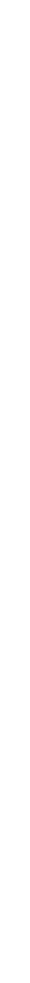

-
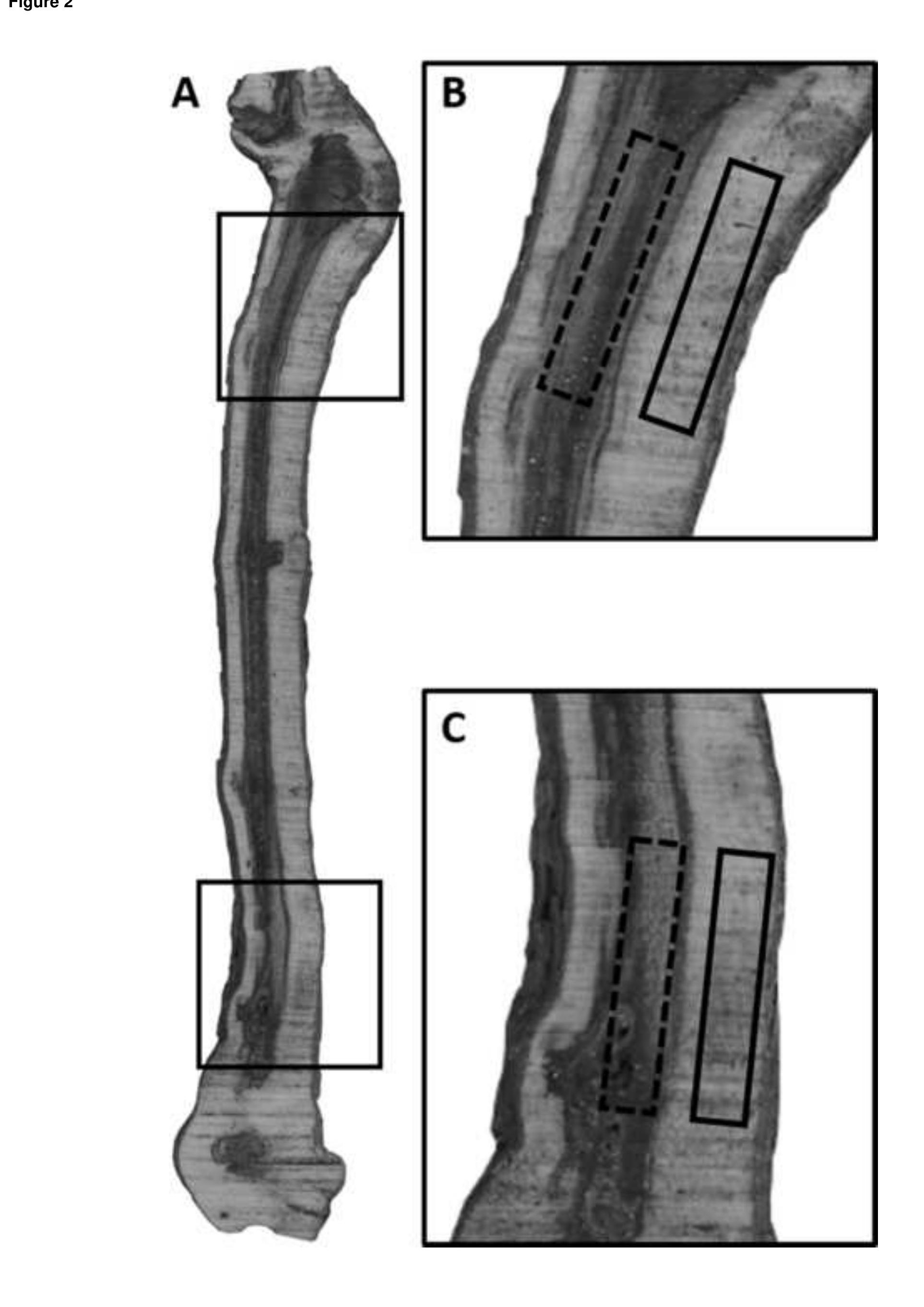

Fire
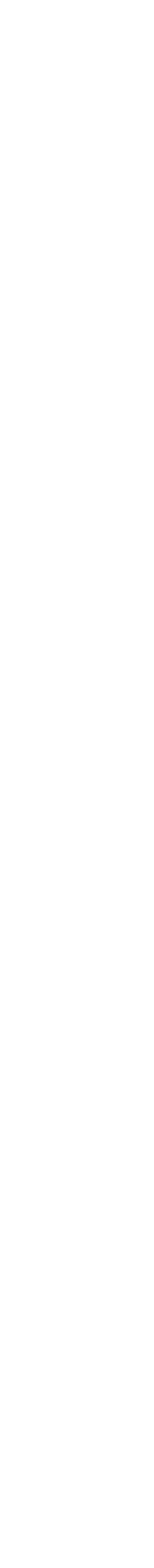
Figure 3
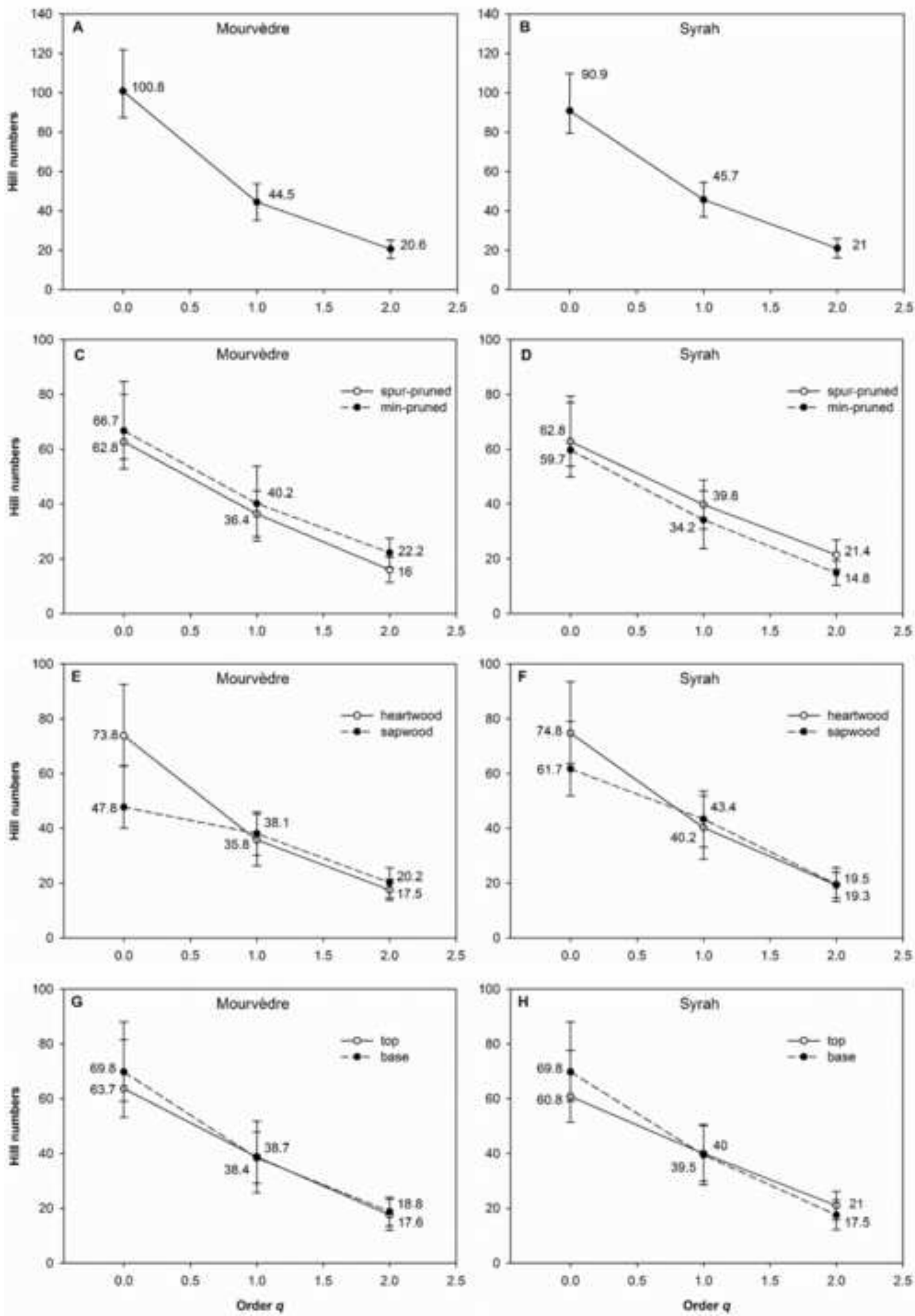


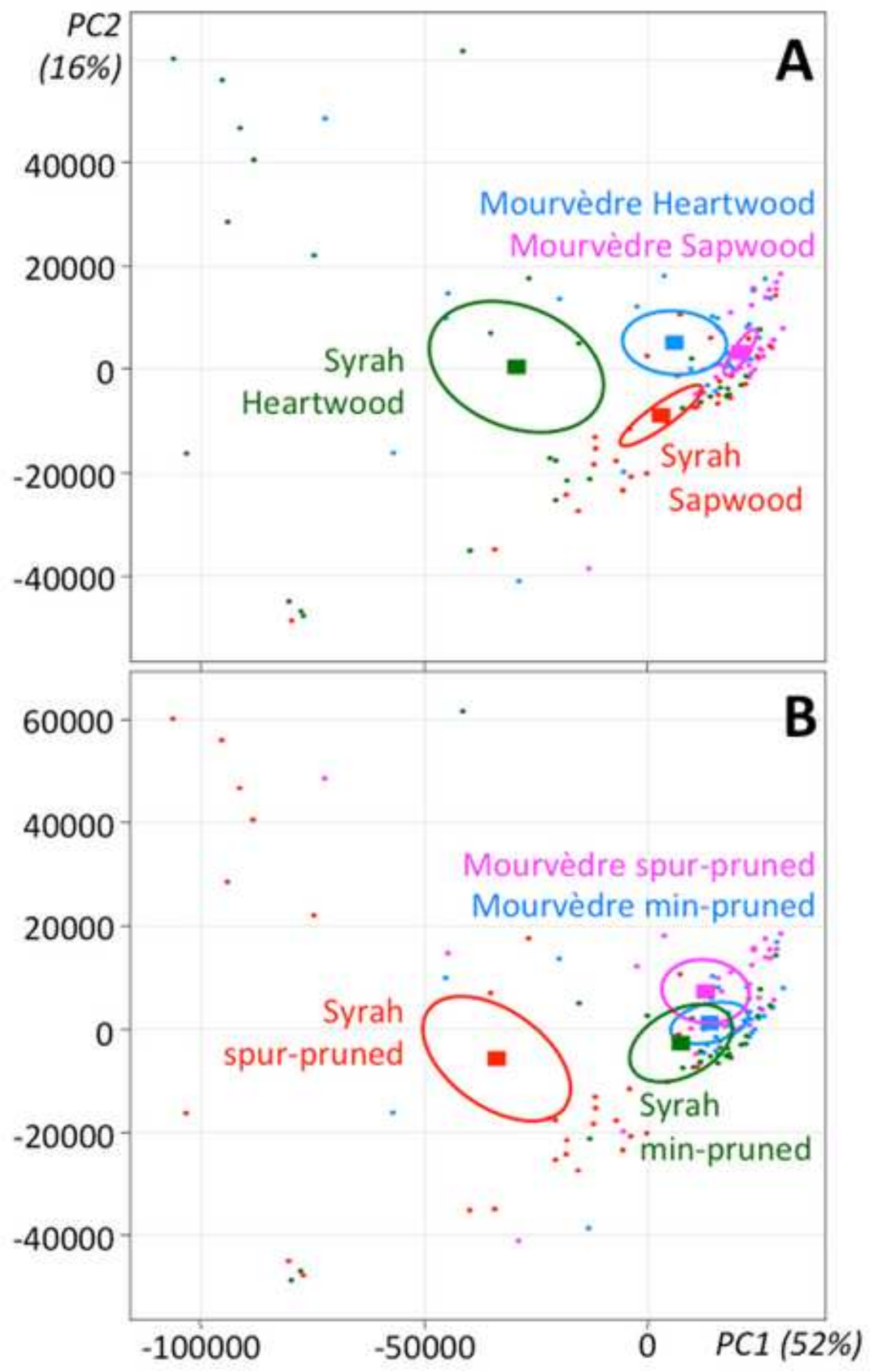


A

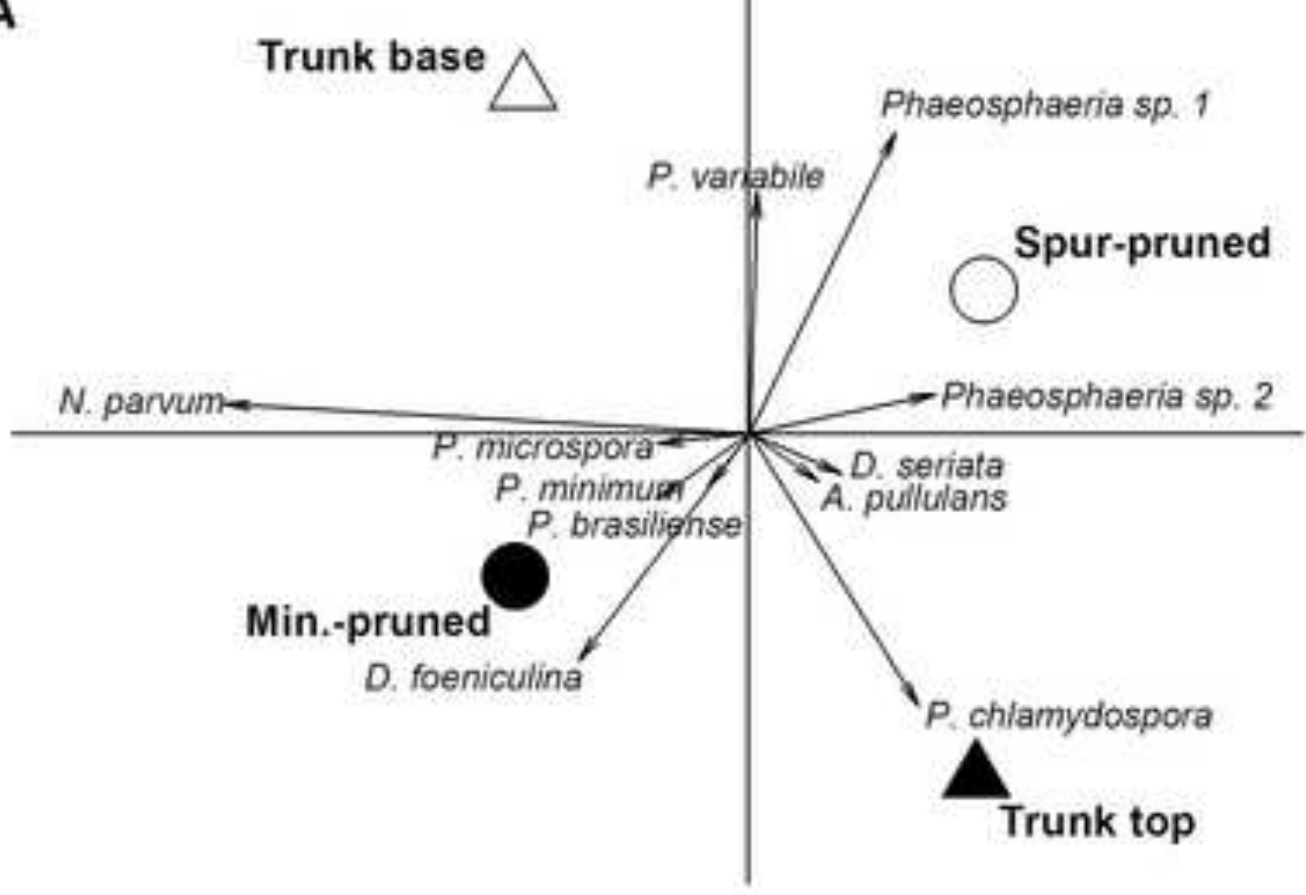

B

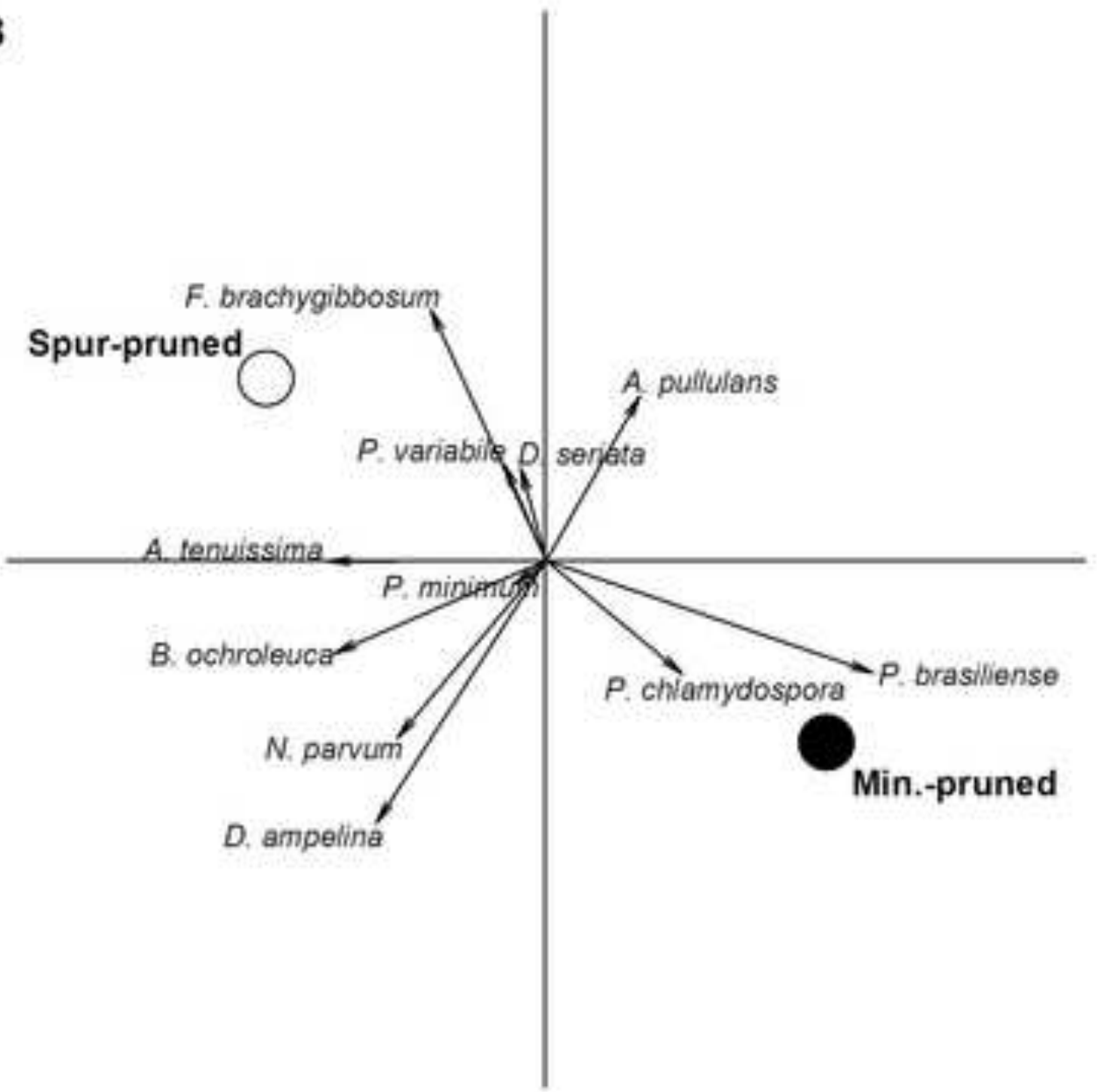

